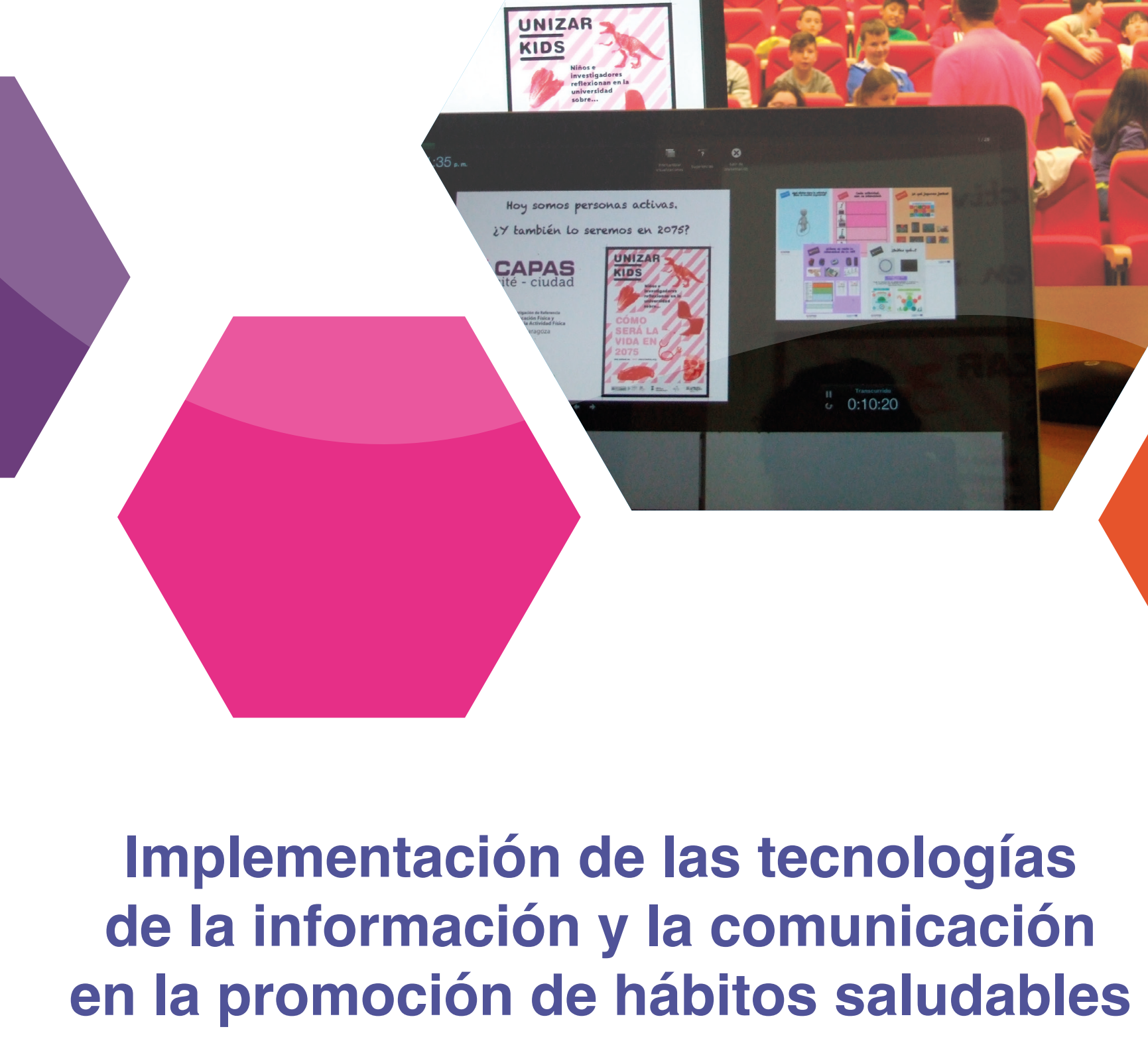

Promoción de hábitos saludables a través de las tecnologías de la información y comunicación: una propuesta de aplicación en los centros educativos y en las clases de Educación Física.

\title{
Coordinación:
}

Javier Rodrigo-Sanjoaquín, Javier Sevil-Serrano, José Antonio Julián Clemente, Eduardo Generelo Lanaspa y Raquel Pérez-Ordás 





\section{Implementación de las tecnologías de la información y la comunicación en la promoción de hábitos saludables}





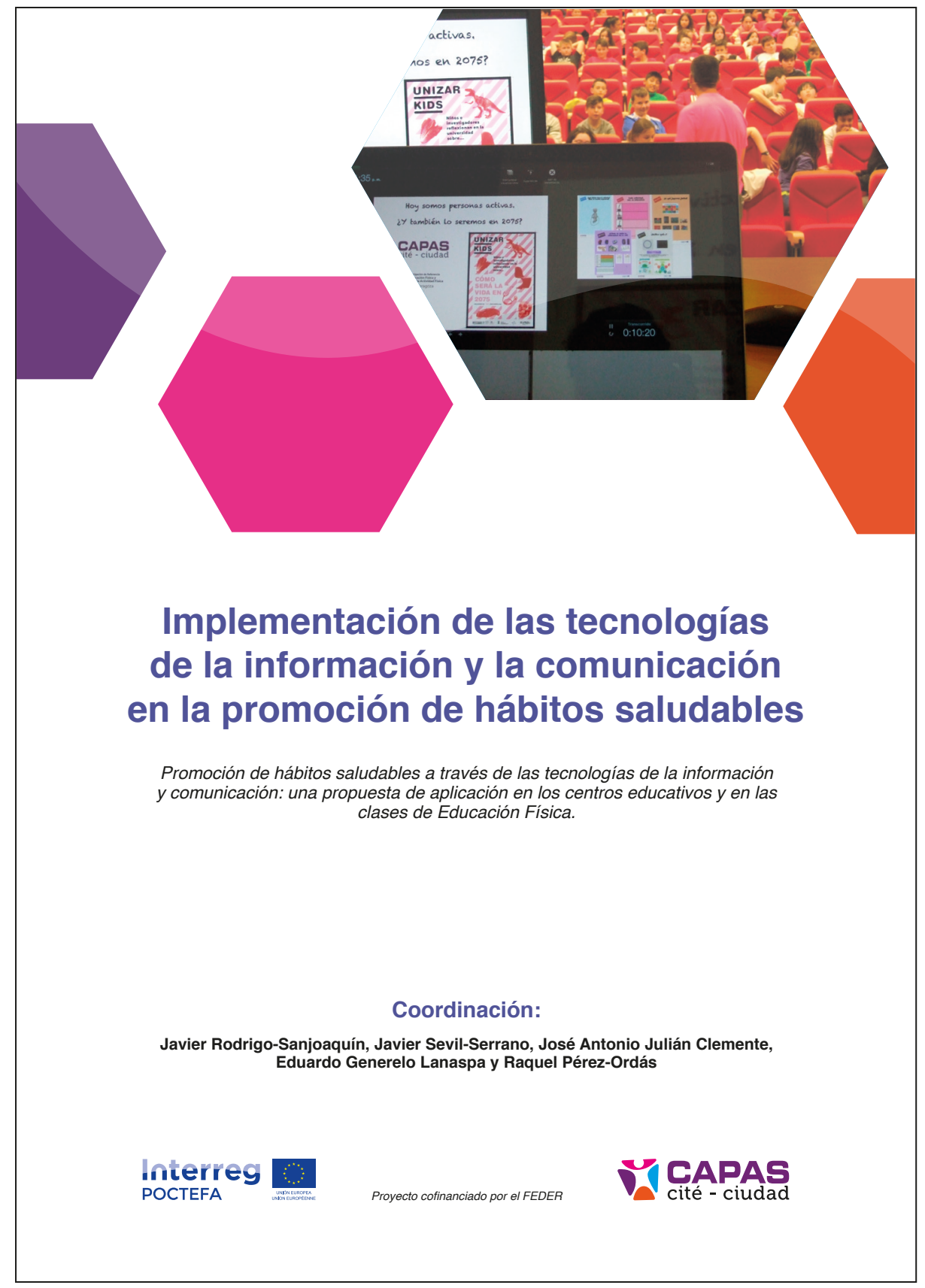

Servicio de Publicaciones.

Universidad de Zaragoza 
() Javier Rodrigo-Sanjoaquín, Javier Sevil-Serrano, José Antonio Julián Clemente, Eduardo Generelo Lanaspa y Raquel Pérez-Ordás

1. ${ }^{\text {a }}$ edición. Huesca, 2019

Edita: Servicio de Publicaciones. Universidad de Zaragoza

ISBN: 978-84-16723-65-2

Imprime: Servicio de Publicaciones. Universidad de Zaragoza

Depósito legal: Z 1019-2019

Una guía práctica para CONECTAR - DESCONECTAR DE LAS TIC.

Aunque cada CONTEXTO requiere una SOLUCIÓN, en este documento encontrarás algunas ACCIONES y ESTRATEGIAS que han sido EFECTIVAS en el uso de las TIC en el programa escolar de promoción de hábitos saludables "Sigue la Huella".

Si te interesan los documentos citados en la guía o quieres obtener más información sobre las estrategias llevadas a cabo ponte en contacto con nosotros en:

Edificio Empresa y Gestión Pública

Despacho 46 Ronda Misericordia,

1 - 22001 Huesca

unizar@capas-c.eu • 974292581

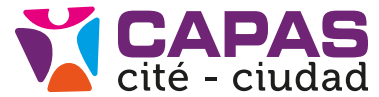

Esta guía ha sido cofinanciada al $65 \%$ por el Fondo Europeo de Desarrollo Regional (FEDER) a través del Programa Interreg V-A España-Francia-Andorra (POCTEFA 2014-2020). El objetivo del POCTEFA es reforzar la integración económica y social de la zona fronteriza España-Francia-Andorra. Su ayuda permite el desarrollo de actividades económicas, sociales y medioambientales transfronterizas a través de estrategias conjuntas a favor del desarrollo territorial sostenible. 


\section{ÍNDICE}

Sobre esta guía

Agradecimientos

1. Nos gusta estar conectados

1.1. ¿En qué nos influye la tecnología?

1.2. Las TIC en la promoción de estilos de vida saludables

2. Introducción a "Sigue la Huella"

2.1. Nuestra experiencia en "Sigue la Huella"

3. Recomendaciones oficiales sobre las TIC y la salud

3.1. Recomendaciones generales sobre el uso de pantallas

3.2. Recomendaciones basadas en las "24-hour movement guidelines"

3.3. Recomendaciones de la UNESCO

4. Las TIC en el sistema educativo

4.1. Aparición de las TIC en el sistema educativo

4.2. TIC en Educación Secundaria Obligatoria

5. Las TIC en el aula

5.1. Las TIC en el alumnado

5.2. Las TIC en el profesorado

6. Barreras

7. Conclusiones

8. Bibliografía 


\section{NOS GUSTA ESTAR CONECTADOS}

Esta guía ofrece acciones y estrategias para los centros de Educación Secundaria con la finalidad de aportar ideas para el uso y aprovechamiento de las TIC en la promoción de hábitos saludables en el alumnado.

Concretamente, en estas líneas os vamos a contar cómo a través del programa escolar "Sigue la Huella" hemos aprovechado las bondades que nos ofrecen las TIC y Tecnologías del Aprendizaje y el Conocimiento (TAC) para promover estilos de vida saludables en el alumnado. La utilización de las TIC y las TAC permiten enriquecer los programas escolares de promoción de comportamientos saludables para motivar al alumnado y mejorar su participación e implicación.

\section{1. ¿EN QUÉ NOS INFLUYE LA TECNOLOGÍA?}

Dentro de dichos componentes, las TIC pueden ser una buena herramienta para motivar al alumnado a realizar más actividad física (AF).

La utilización de las nuevas tecnologías es, en la actualidad, una cuestión prioritaria tanto en las agendas políticas de casi todos los países europeos como en la misma Unión Europea (UE). El Plan de Acción e-Europa (2000) de la UE perfila cuáles son los pasos necesarios para avanzar hacia la sociedad de la información y subraya, claramente, el papel central que juega la educación para hacer de dicha Sociedad de la Información una realidad. El estudio de la Organización para la Cooperación y el Desarrollo Económico (OCDE), Aprendiendo a cambiar: Las Nuevas Tecnologías en las escuelas
(2001) muestra cómo estos nuevos recursos están transformando la educación y el aprendizaje del alumnado en todo el mundo.

Las herramientas digitales y las TIC nos han permitido crear entornos de comunicación nuevos. Estos nos permiten obtener, transmitir y compartir, de inmediato, abundante información. Nos encontramos inmersos en la llamada sociedad de la información. Esta sociedad (tecnológica) está impregnando todos los estamentos e implicando a los ciudadanos, sobre todo a los más jóvenes, en todas sus actividades profesionales y sociales, desde su trabajo, formación, hasta el consumo y la comunicación.

Por otro lado, las TIC en general y, muy concretamente, las vinculadas a teléfonos móviles, tabletas, smartwatchs, prendas de ropa inteligentes y otros dispositivos, están ya muy extendidos entre toda la población y, especialmente, en adolescentes. Por este motivo, con la finalidad de acercarnos a herramientas tecnológicas que pueden ser motivantes para ellos, las TIC pueden ofrecer también la oportunidad de fomentar hábitos saludables. Este tipo de intervenciones pueden potenciar o complementar el impacto de las estrategias empleadas hasta el momento al utilizar un canal potencialmente cercano y atractivo para la población adolescente.

El profesorado debe buscar constantemente nuevas estrategias e instrumentos de enseñanza, como el uso del ordenador, la pizarra y el teléfono móvil, que faciliten al alumnado su aprendizaje. Concretamente, el uso de la tecnología móvil en educación puede ser una poderosa herramienta educativa debido a sus características: portabilidad, inmediatez, conectividad, ubicuidad y adaptabilidad (Cantillo y otros, 2012).

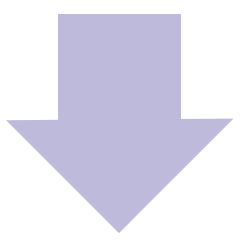

¿DES-CONECTAS?

Descanso de las TICs

\begin{tabular}{l|l|} 
Naturaleza & Contacto físico \\
\hline
\end{tabular}




\subsection{LAS TIC EN LA PROMOCIÓN DE} ESTILOS DE VIDA SALUDABLES

En las diversas áreas curriculares, tanto la elevada carga lectiva (secundaria y bachillerato), como la abundancia de contenidos (en base a los criterios y estándares de evaluación curriculares), pueden dificultar, en ocasiones, la implementación de estas tecnologías debido a la falta de tiempo. Pero, por otra parte, las TIC nos ofrecen un gran abanico de posibilidades educativas en determinados contenidos. Por ejemplo, por medio de las redes sociales y aplicaciones móviles, existe la posibilidad de incentivar la práctica de AF en el alumnado.

Asimismo, a través de herramientas informáticas o aplicaciones móviles se puede codificar, almacenar y transferir datos sobre la propia AF, especialmente desde la EF escolar. De esta manera se involucra al alumnado y se propicia el desarrollo de proyectos de aprendizaje interdisciplinares entre diversas materias (ej., proyectos de EF con Matemáticas, Informática y Tecnología).

Es preciso destacar que en los institutos cada vez se utilizan más estas tecnologías, concretamente, el uso del "Smartphone" o teléfono móvil. Esto se debe, no solo a la normalización y generalización de uso de las propias TIC, sino también a la accesibilidad a estos dispositivos móviles por parte de la mayoría de los adolescentes. El último informe de Distrendia (2017) señaló que el 99\% de los adolescentes españoles poseía un teléfono móvil. Además, en un estudio reciente llevado a cabo en adolescentes españoles se apreció que el teléfono móvil es ya el medio tecnológico de pantalla más utilizado, por encima de la televisión, el ordenador y los videojuegos (Adelantado-Renau et al., 2018). Por todas estas razones, la irrupción de las TIC no solo en el ámbito escolar sino también en nuestro día a día no puede ser ignorada. Conseguir adaptar las nuevas tecnologías que emergen continuamente en la sociedad se configura como un elemento clave en la promoción de comportamientos saludables.

\section{¡Docente, pon atención!}

A pesar de todos los beneficios asociados a las TIC, Carbonell, (2002) señaló que introducir un nuevo recurso tecnológico en la enseñanza no significa que cause una mejora educativa automáticamente.

Por otro lado, la falta de medios tecnológicos necesarios en los centros educativos limita la posibilidad de inclusión en la enseñanza, por lo que el teléfono móvil personal del alumnado se convierte en una posible opción (Escarvajal, 2018). Aun así, puede existir un sector del alumnado que no tenga teléfono, conexión a internet o que la red WiFi no pueda cubrir ciertas zonas del centro educativo, encontrándonos, por lo tanto, con dificultades técnicas o barreras a la hora de desarrollar este tipo de actividades (Román, 2012).

Las TIC nos ofrecen la posibilidad de servir de apoyo al profesorado, al alumnado o a ambos agentes a la vez. En el siguiente epígrafe se recogen las principales ventajas e inconvenientes para el profesorado y el alumnado en el uso de las TIC en la educación.

\begin{tabular}{|c|c|}
\hline Ventajas & Inconvenientes \\
\hline $\begin{array}{l}\text { - Ofrece una formación continua para el profesor. } \\
\text { - Puede facilitar compartir recursos. } \\
\text { - Facilita la evaluación. } \\
\text { - Posibilita el seguimiento del alumnado en clase. }\end{array}$ & $\begin{array}{l}\text { - Puede requerir una formación previa. } \\
\text { - Requiere mayor dedicación por parte del profesorado: cursos } \\
\text { de alfabetización, tutorías virtuales, búsqueda de información } \\
\text { en internet y escribir correos. } \\
\text { - Implica la necesidad de comprar y actualizar equipos y } \\
\text { programas. }\end{array}$ \\
\hline
\end{tabular}

\begin{tabular}{|c|c|}
\hline Ventajas & Inconvenientes \\
\hline $\begin{array}{l}\text { - Aumenta el interés en el aprendizaje. } \\
\text { - Aumento de la motivación. } \\
\text { - Facilita la comunicación. } \\
\text { - Pomenta la cooperación (uso de un espacio digital común). } \\
\text { educativo un fácil acceso a la información y recursos } \\
\text { - Mejora la competencia digital. }\end{array}$ & $\begin{array}{l}\text { - Genera distracciones en ocasiones. } \\
\text { - Genera ansiedad y dependencia si el uso es inadecuado. } \\
\text { - Dificulta el desarrollo de habilidades sociales. } \\
\text { - Genera cansancio visual y otros problemas físicos. } \\
\text { - Requiere de una explicación previa. }\end{array}$ \\
\hline
\end{tabular}




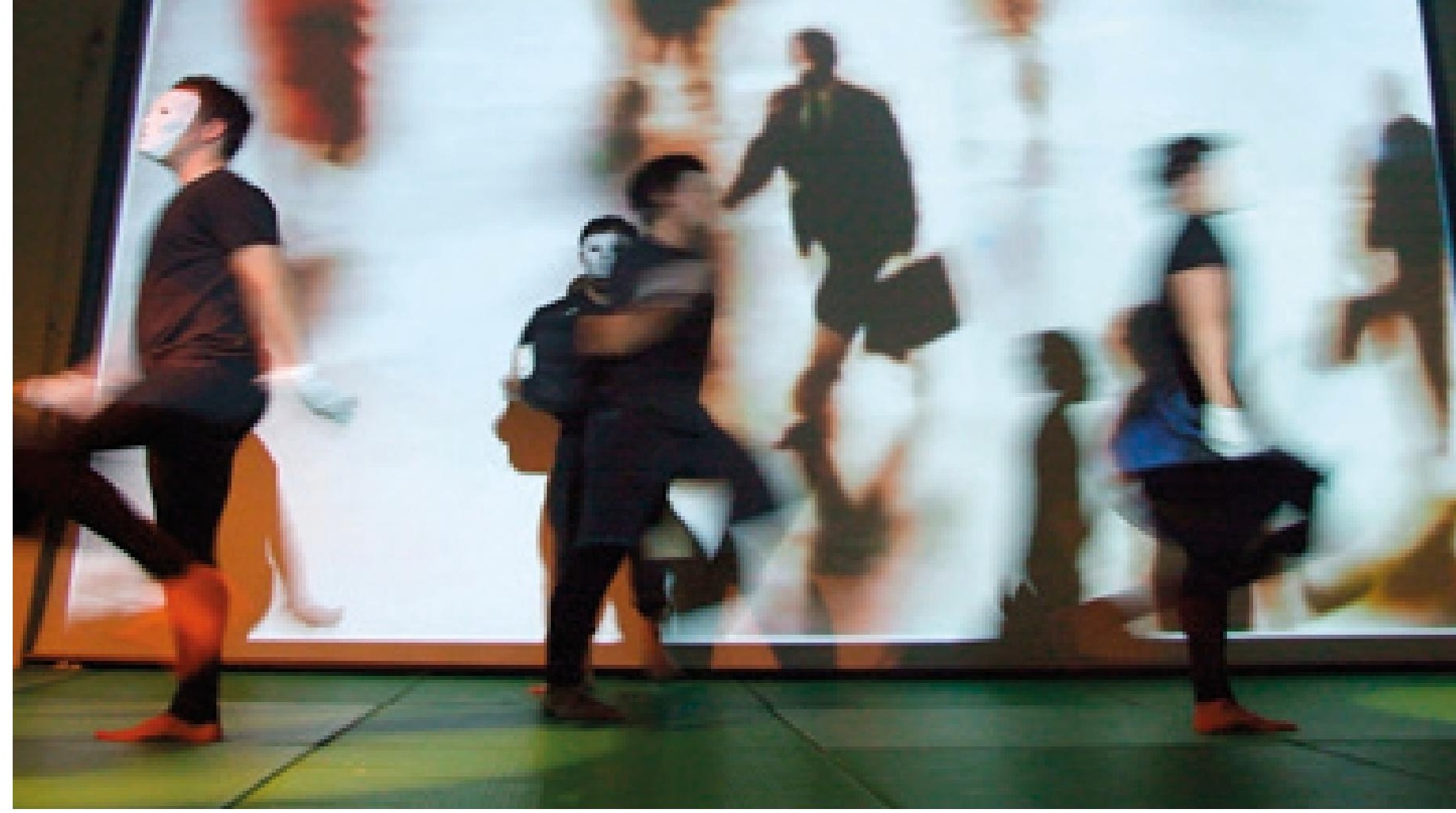

\section{INTRODUCCIÓN a "SIGUE LA HUELL"}

2.1. NUESTRA EXPERIENCIA EN" "SIGUE LA HUELLA"

En este documento se recogen una serie de orientaciones basadas en la aplicación del programa escolar "Sigue la Huella". Como se ha contextualizado previamente, en el programa estuvieron implicados varios agentes de la comunidad educativa. De for- ma más concreta se involucró tanto a tutores (guía sobre el plan de acción tutorial; PAT), familias (guía para las familias y el equipo docente), profesorado (guía sobre el bienestar docente), alumnado y a la administración educativa.

El instituto se ha mostrado como un entorno idóneo para promover estilos de vida activos y saludables en el alumnado (Sevil et al., 2018). Además,

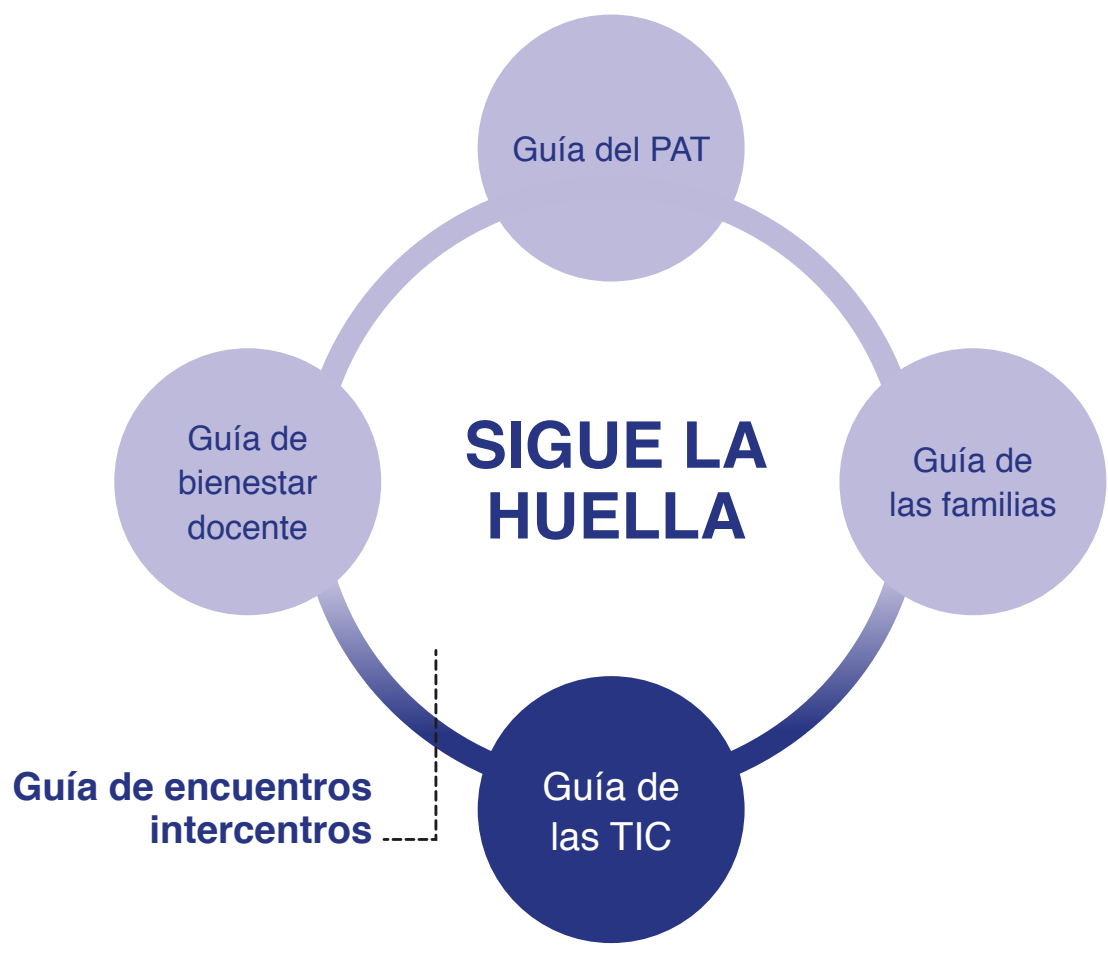


las conductas saludables adquiridas en esta etapa tienen una mayor probabilidad de mantenerse en la edad adulta (Telama et al., 2005).

Cabe destacar que el programa "Sigue la Huella" recibió el primer premio Estrategia NAOS en 2012, así como el primer accésit del Premio Estrategia NAOS en 2017 a la mejor estrategia de promoción de la práctica de AF en el ámbito escolar. Este galardón fue concedido por el Ministerio de Sanidad, Consumo y Bienestar Social.

De manera específica, el programa escolar "Sigue la Huella" tiene como objetivos:

1. Crear un entorno más activo y saludable con la participación de todos los agentes de la comunidad educativa.

2. Desarrollar competencias y habilidades que favorezcan estilos de vida más saludables en los adolescentes.

3. Promover y mejorar los hábitos saludables del alumnado.

Los componentes principales en los que se apoya el programa son:

1. Los recreos.

2. EI PAT.

3. Las diferentes asignaturas escolares, especialmente la EF.

4. La difusión de la información.

5. La participación en programas institucionales y actividades especiales o efemérides.

Dentro del programa escolar "Sigue la Huella" se introdujeron las TIC con objeto de promover comportamientos saludables en el alumnado. Se fomentó la participación e involucración del alumnado utilizando las TIC, concretamente, a través del propio blog del instituto y mediante el uso de pantallas situadas en zonas comunes. En dichas pantallas se proyectaron galerías de fotos sobre las actividades realizadas en el programa escolar. También se utilizaron determinadas aplicaciones educativas en las unidades didácticas (UD) de EF, así como acelerómetros, pulsómetros, brújulas, GPS, etc.

Dentro del contexto escolar de referencia, las TIC también se pueden utilizar como recurso tecnológico para incidir en la satisfacción de las tres necesidades psicológicas básicas (NPB) que se definen en la teoría de la autodeterminación (Deci et al., 2000). Este sustento teórico señala que existen tres NPB: la autonomía, la competencia y las relaciones sociales.
Según Deci y Ryan (2000), la satisfacción de las tres NPB es necesaria para que el alumnado desarrolle una motivación más autodeterminada que influirá, a su vez, en una serie de consecuencias de índole afectiva, cognitiva y comportamental. Es decir, si el alumnado percibe que puede tomar decisiones en su proceso de enseñanza-aprendizaje (satisfacción de autonomía), se siente eficaz en las tareas que realiza (satisfacción de competencia) y mantiene relaciones positivas con sus compañeros (satisfacción de las relaciones sociales) tienen una mayor posibilidad de estar motivado en sus clases $y$, consecuentemente, de adoptar una serie de consecuencias más adaptativas (ej. diversión, aprendizaje, rendimiento académico, etc.). En este sentido, el profesorado puede apoyar las tres NPB en su alumnado tanto con discurso verbal como a través de las TIC.

Mediante las propuestas presentadas en esta guía para conseguir un entorno saludable y promocionar un estilo de vida saludable, se busca, también, favorecer el bienestar del alumnado, su desarrollo personal y las relaciones entre ellos.

El propio uso de las TIC se desglosará en el apartado "Las TIC en el aula de Educación Física". Para ello, se identificarán tres de los elementos terminológicos que se usaron en el programa "Sigue la Huella": el programa CALADU, el uso de pantallas en el centro escolar y el propio blog del instituto.

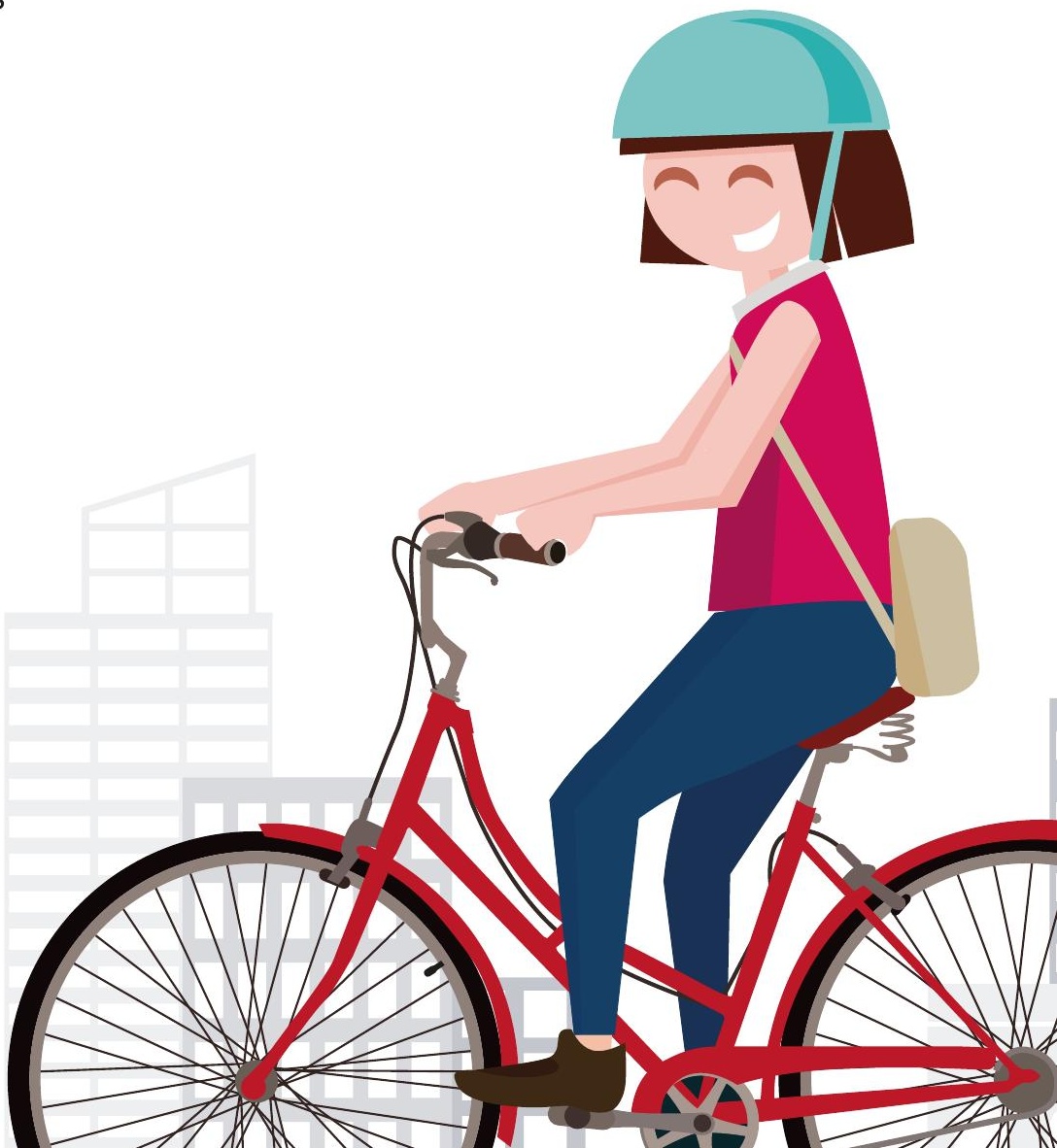




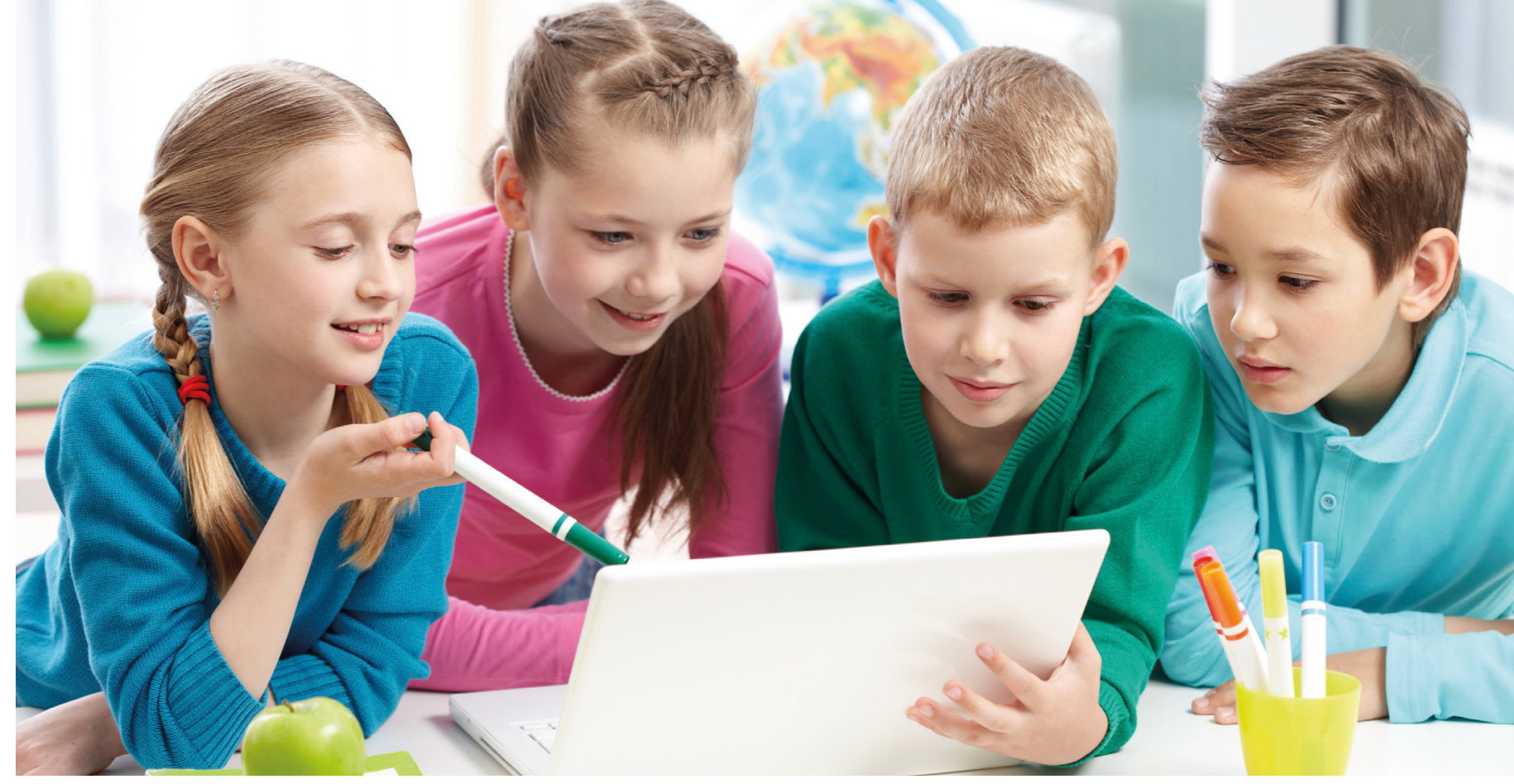

\section{RECOMENDACIONES OFICIALES SOBRE LAS TIC Y LA SALUD}

Una vez contextualizado el programa escolar "Sigue la Huella", en este apartado se detallan las principales recomendaciones sobre hábitos saludables propuestas por diferentes organizaciones y entidades internacionales.

\subsection{Recomendaciones generales sobre pantallas}

En nuestra sociedad, las pantallas actúan como conexión entre las personas y el resto del mundo como un elemento vertebrador. Sin embargo, la sobreexposición a estas afecta directamente a la salud de la población infantil y juvenil.

Se estima que los adolescentes de entre 12 y 16 años dedican al menos 3 horas diarias a navegar por internet y usar el teléfono móvil. Este tiempo dedicado a las pantallas aumenta progresivamente con la edad (Conde, 2018). Un estudio realizado en Estados Unidos señaló que los niños de menos de 8 años dedicaron más de 2 horas diarias a diferentes medios electrónicos de pantalla. Los niños entre 8 y 12 años dedicaron 6 horas, mientras que los niños mayores de 12 años más de 9 horas (Common Sense Media, 2015 y 2017).

En relación al tiempo sedentario de pantalla, desde hace más de una década prevalecen las recomendaciones establecidas por la American Association of Pediatrics (2001) que establecen que el tiempo de uso de la televisión no debía sobrepasar las 2 horas en niños y adolescentes de 5 a 17 años. Sin embargo, pese a la emergente aparición y modernización de nuevos dispositivos electrónicos (ej., teléfono móvil, videojuegos, ordenador, tabletas, etc.) estas recomendaciones han permanecido intactas, sin ningún tipo de modificación.

Por lo tanto, es urgente que la población adolescente desarrolle habilidades que le permitan realizar una correcta gestión de uso de estas pantallas, así como, en la medida de lo posible, se alejen de conductas sedentarias. Para ello, tanto una correcta alfabetización digital, como conocer las recomendaciones de tiempo de pantalla relacionadas con la salud se consideran asuntos prioritarios.

Recientemente, se han publicado en España las primeras recomendaciones para toda la población sobre AF, sedentarismo y tiempo de pantalla, basadas en las ya existentes a nivel internacional (Ministerio de Sanidad, Servicios Sociales e Igualdad, 2018).

A continuación, se detalla el modelo canadiense de 24 horas en el que se destacan no solo las recomendaciones de tiempo de pantalla sino también las recomendaciones de AF y sueño. 


\subsection{Recomendaciones basadas en las "24-hour movement guidelines"}

Recientemente, una serie de expertos han elaborado un nuevo paradigma teórico "Canadian 24-hour movement guidelines" que señala que la duración diaria del tiempo es finita (i.e., tiene un máximo de 24 horas).

Bajo esta premisa, la AF, el tiempo sedentario y la duración del sueño representan tres comportamientos relacionados con la salud que prevalecen e interaccionan durante las 24 horas que tiene el día (Chaput et al., 2014; Tremblay et al., 2016), por lo que el tiempo dedicado a un comportamiento afecta irremediablemente al tiempo dedicado a los otros dos. Estos autores canadienses ratifican las recomendaciones anteriormente expuestas para tiempo de pantalla y detallan también las recomendaciones de AF y duración de sueño en niños y adolescentes de 5 a 17 años: AF moderada-vigorosa (al menos 60 minutos diarios), tiempo de pantalla ( $<2$ horas diarias) y duración de sueño (9-11 horas en niños y 8-10 horas en adolescentes) (Tremblay et al., 2016).

Estos autores también señalan que no es posible precisar unas recomendaciones para todos los comportamientos que ocupan las 24 horas del día ya que los rangos de algunas recomendaciones no son completamente cerrados (ej., 8-10 horas de duración de sueño). Sin embargo, señalan la importancia de limitar el tiempo de estar sentado, así como la importancia de realizar actividad ligera varias horas al día.

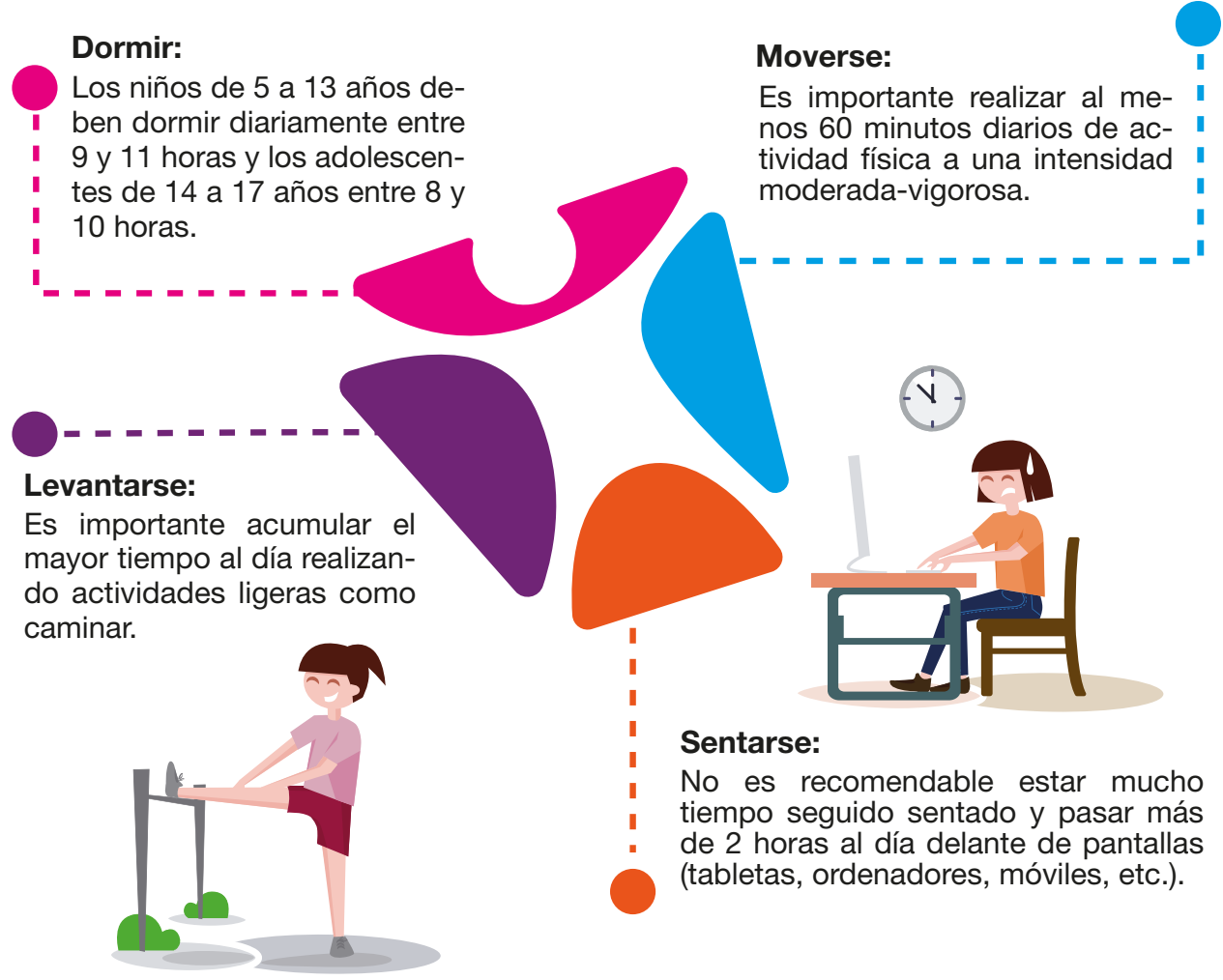

El cumplimiento de estas tres recomendaciones se ha visto asociado positivamente con mejoras en la composición corporal, capacidad cardiorrespiratoria y aptitud músculo esquelética, el rendimiento académico y la cognición, la regulación emocional, los comportamientos prosociales, la salud cardiovascular y metabólica y la calidad de vida.

Por tanto, es importante no solo cumplir las recomendaciones de AF, sino también las de duración de sueño y tiempo de pantalla para maximizar los beneficios en la salud. 


\subsection{Recomendaciones de la UNESCO}

Por último, la UNESCO cree que las tecnologías móviles pueden ampliar y enriquecer las oportunidades educativas en distintos contextos. Hay cada vez más datos que indican que los omnipresentes dispositivos móviles, en particular los teléfonos móviles y, más recientemente, las tabletas, son utilizados por educandos y docentes de todo el mundo para acceder a información, simplificar la administración y facilitar el aprendizaje de una forma nueva e innovadora (UNESCO, 2016).

El aprendizaje móvil es una rama de las TIC en la educación. Sin embargo, dado que emplea tecnología más asequible y más fácil de adquirir y utilizar por cuenta propia que los ordenadores fijos, exige una nueva conceptualización de los modelos tradicionales de uso y aplicación de las tecnologías.

Ventajas del aprendizaje móvil según la UNESCO (UNESCO, 2016):

1. Mayor alcance e igualdad de oportunidades en la educación.

2. Facilidad para el aprendizaje personalizado.

3. Respuesta y evaluación inmediatas.

4. Aprendizaje en cualquier momento y lugar.

5. Empleo productivo del tiempo en el aula.

6. Creación de nuevas comunidades de educandos.

7. Apoyo al aprendizaje en lugares concretos.

8. Mejora del aprendizaje continuo.

9. Vínculo entre la educación formal y no formal.

10. Mínimos trastornos para el aprendizaje en las zonas de conflicto y de desastre.

11. Apoyo a los educandos con diversidad funcional.

12. Mejora de la comunicación y la administración.

13. Máxima eficacia en función de los costos.

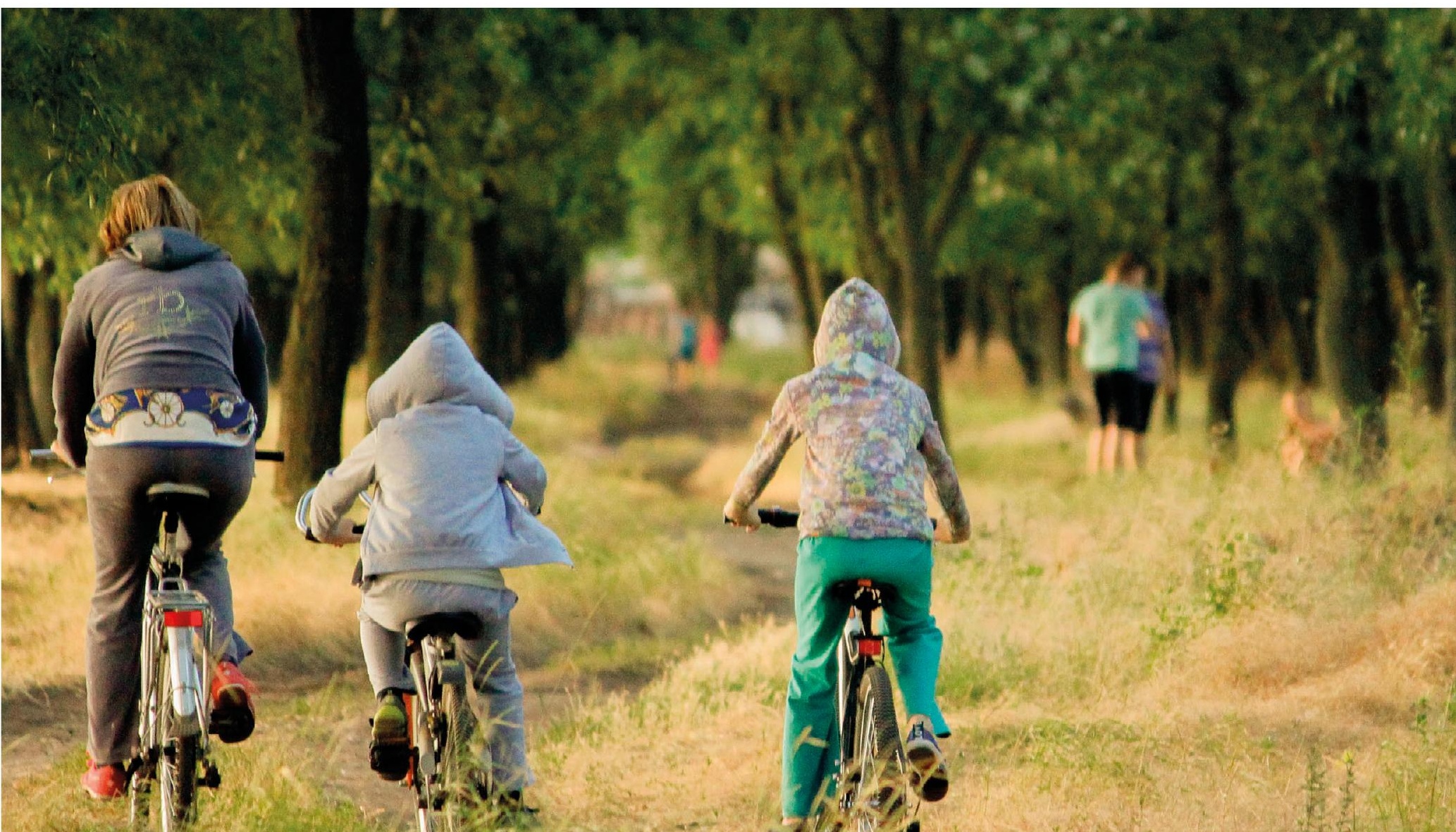




\section{TIC EN EL SISTEMA EDUCATIVO}

En este apartado se detalla la evolución de las TIC en el sistema educativo, desde su inclusión hasta la implementación actual dentro de las competencias clave y criterios de evaluación.

\subsection{APARICIÓN DE LAS TIC EN EL SISTEMA EDUCATIVO}

La inclusión de las TIC en el sistema educativo actual se produjo por primera vez con la Ley Orgánica 1/1990, de 3 de octubre, de Ordenación General del Sistema Educativo (LOGSE). En ella se hacen diversas referencias a la formación en el ámbito del lenguaje audiovisual y a la capacitación del alumnado para analizar de forma crítica los mensajes a través de los diferentes medios de comunicación. En esta ley educativa las nuevas tecnologías aludían a ordenadores de aula, videocámaras, radiocasetes, etc.

Sin embargo, hasta la publicación de la Ley Orgánica 10/2002, de 23 de diciembre, de Calidad de la Educación (LOCE), no pasan a denominarse como Tecnologías de la información y la Comunicación (TIC).

Con la Ley Orgánica 2/2006, de 3 de mayo, de Educación (LOE), se incluyó por primera vez a las TIC desde la etapa de educación infantil hasta el resto de etapas educativas. Además, se hizo implícito el compromiso de la administración de aportar a los centros las infraestructuras necesarias para el uso de las TIC por parte del alumnado.

En la actual Ley Orgánica 8/2013, de 9 de diciembre, para la Mejora de la Calidad Educativa (LOMCE), se mantienen las premisas formuladas en la ley anterior, delegándose su protagonismo, uso e implementación a los currículos autonómicos. Además, desde el Real Decreto 1105/2014, de 26 de diciembre, por el que se establece el currículo básico de Educación Secundaria y Bachillerato, se establecen las TIC dentro de los elementos transversales a trabajar desde todas las áreas curriculares.

En cuanto a las propias competencias, el uso de las TIC pretende favorecer en el alumnado la adquisición de ciertas competencias clave de forma directa (competencia matemática y competencias básicas en ciencia y tecnología y competencia digital) e indirecta (competencia de aprender a aprender) en cada nivel y etapa.

Las nuevas tecnologías son, por tanto, un claro reflejo de los cambios producidos en la sociedad actual. Su inclusión en el aula suscita el desarrollo de nuevas metodologías de enseñanza en el proceso de enseñanza-aprendizaje. 


\subsection{TIC EN EDUCACIÓN SECUNDARIA OBLIGATORIA}

La aplicación de las TIC en el currículo de EF se estructura en base a dos vertientes. Por un lado, la especificación de los criterios de evaluación (CE) y estándares de aprendizaje (EA) y, por otro, la presencia de la competencia clave digital en la asignatura.

a) Con relación a los criterios de evaluación y estándares de aprendizaje.

\section{a.1) En $3^{\circ}$ de ESO.}

Crit.EF.6.10. Utilizar las Tecnologías de la Información y la Comunicación en el proceso de aprendizaje, para buscar, analizar y seleccionar información relevante, elaborando documentos propios, y haciendo exposiciones y argumentaciones de los mismos de los contenidos/temas/proyectos impartidos durante el curso.

\section{a.2) En $4^{\circ}$ de ESO.}

Crit.EF.6.12. Utilizar eficazmente las TICs en el proceso de aprendizaje, para buscar, seleccionar y valorar informaciones relacionadas con los contenidos del curso, comunicando los resultados y conclusiones en el soporte más adecuado.

\section{b) A nivel metodológico se invita al profesorado a utilizar las TIC encaminadas a:}

1) La búsqueda, selección, recogida y procesamiento de información relacionada con la EF para la realización de los trabajos solicitados por el profesorado (presenta y/o publica elaboraciones en las que se maneja imagen, audio, vídeo, herramientas web 2.0, etc.)

2) Los medios informáticos y audiovisuales pueden ser utilizados en el proceso de enseñanza-aprendizaje como herramienta de tratamiento rápido y significativo de las informaciones recogidas. El creciente número de herramientas digitales relacionadas con la AF (GPS y rutas, monitorización de ritmo cardiaco, vídeos, ...) y las aplicaciones generales (herramientas de presentación, editores de imagen, audio y vídeo, redes sociales, ...) posibilitan un aprendizaje más significativo de la EF.

3) Conocer y utilizar recursos y aplicaciones como herramientas en el proceso de aprendizaje. Se contribuye de esta forma a preparar al alumnado a vivir en un mundo digital, un alumnado capaz de trabajar con la información y convertirla en conocimiento, que maneja las herramientas digitales y que puede procesar la información en múltiples formatos.

4) El uso de webs, blogs, redes sociales, u otros espacios digitales, en los que participen tanto el profesor como el alumnado, pueden ser un medio muy útil para compartir, intercambiar y ofrecer información para potenciar el conocimiento sobre la mejora de la salud y otras propuestas.

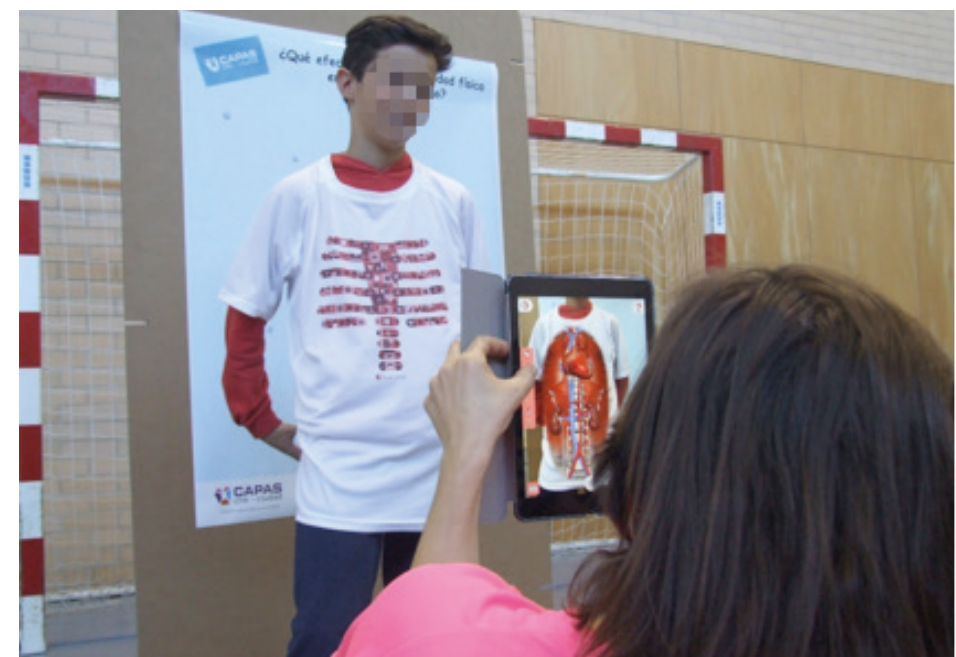




\section{LAS TIC EN EL AULA.}

Se detalla dentro de este punto la aplicación y uso de algunas TIC con objeto de que el alumnado mejore su competencia digital y adquiera recursos tecnológicos que le ayuden a desarrollar y gestionar un estilo de vida activo y saludable. Por otro lado, se describe el uso de las TIC que puede utilizar el profesorado para ayudar al alumnado a adquirir las competencias señaladas.

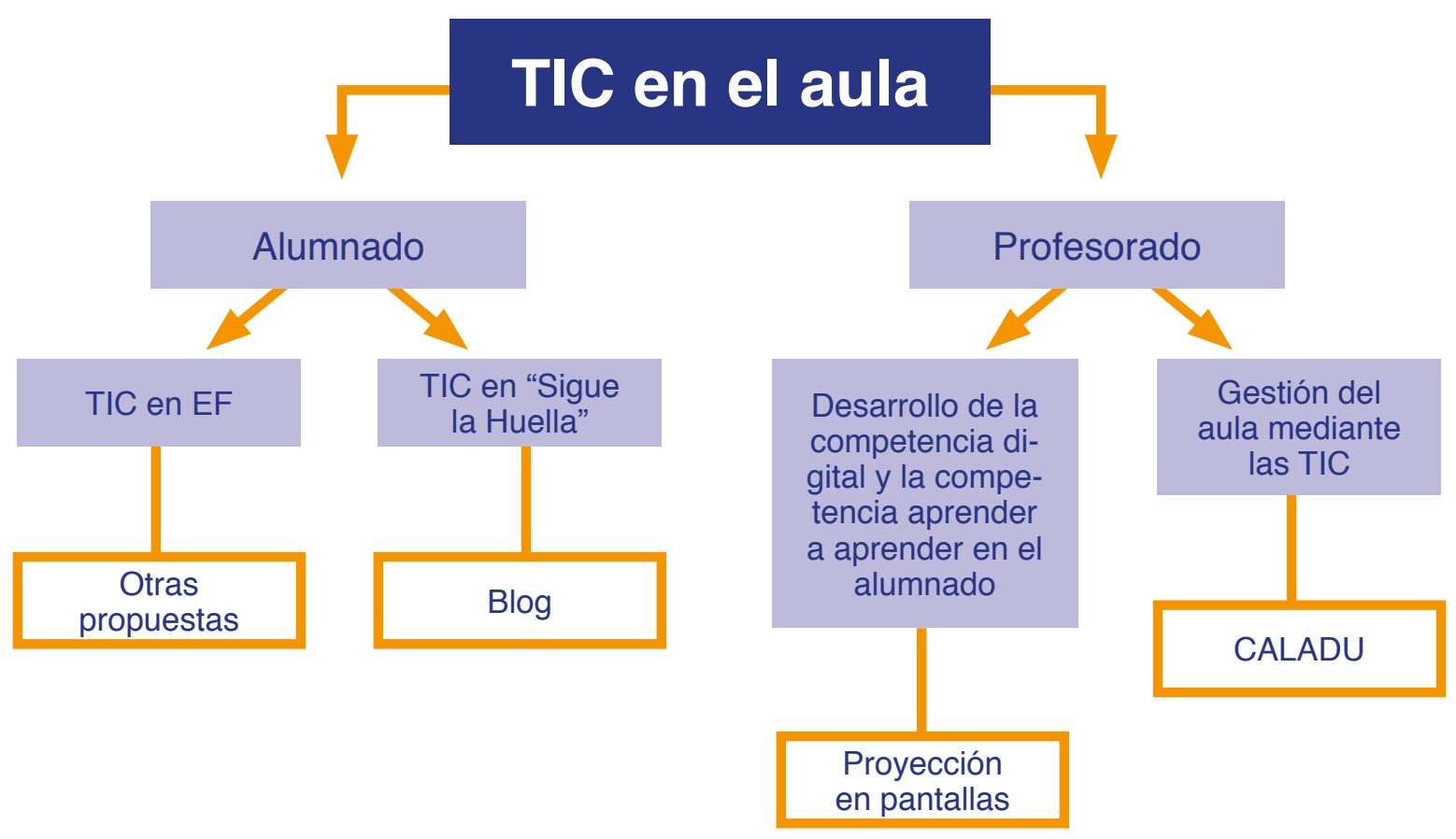

\subsection{TIC EN EL ALUMNADO}

Los criterios de evaluación y estándares de aprendizaje se detallan a nivel autonómico en la ORDEN ECD/489/2016, de 26 de mayo, por la que se aprueba el currículo de Educación Secundaria y se autoriza su aplicación en los centros docentes de la Comunidad Autónoma de Aragón. Como debemos recordar, la decisión de la administración educativa fue la de simplificar los elementos curriculares en $1^{\circ}$ y $2^{\circ}$ de ESO, por lo que haremos referencia a los CE y EA de final de los niveles.

\section{TIC en EF}

A continuación, se detallan una serie de propuestas que pueden permitir al docente integrar las TIC en las clases de EF. Para ello, con el objetivo de facilitar y clarificar la labor al docente, se ha establecido una relación entre las propuestas que ayudan a adquirir esta competencia digital y cómo se relacionan con los criterios/estándares de evaluación del bloque VI "Gestión de Vida Activa y Valores" que aluden a las TIC. 


\begin{tabular}{|c|c|c|c|}
\hline Curso & $\begin{array}{l}\text { Criterio de } \\
\text { evaluación }\end{array}$ & Estándar de evaluación & Propuestas \\
\hline \multirow{2}{*}{$3^{\circ} \mathrm{ESO}$} & \multirow{2}{*}{$\begin{array}{l}\text { Crit.EF.6.10. Utilizar las } \\
\text { TIC en el proceso de } \\
\text { aprendizaje, para buscar, } \\
\text { analizar y seleccionar } \\
\text { información relevante, } \\
\text { elaborando documentos } \\
\text { propios, y haciendo expo- } \\
\text { siciones y argumentacio- } \\
\text { nes de los mismos de los } \\
\text { contenidos/temas/ pro- } \\
\text { yectos impartidos durante } \\
\text { el curso. }\end{array}$} & $\begin{array}{l}\text { Est.EF.6.10.1. } \\
\text { Utiliza las TIC para elaborar } \\
\text { documentos digitales propios } \\
\text { (texto, presentación, imagen, } \\
\text { video, sonido, ...), como resul- } \\
\text { tado del proceso de búsqueda, } \\
\text { análisis y selección de infor- } \\
\text { mación relevante de los conte- } \\
\text { nidos/temas/proyectos imparti- } \\
\text { dos durante el curso. }\end{array}$ & $\begin{array}{l}\text {-Realización de un montaje } \\
\text { audiovisual con música y otro } \\
\text { tipo de efectos de edición (ex- } \\
\text { presión corporal, acrosport). } \\
\text { - Grabación y análisis de } \\
\text { ejecución de movimientos } \\
\text { (gestos técnicos o aspectos } \\
\text { tácticos específicos) median- } \\
\text { te videocámara o cámara de } \\
\text { móvil. }\end{array}$ \\
\hline & & $\begin{array}{l}\text { Est.EF.6.10.2. } \\
\text { Expone y defiende los trabajos } \\
\text { elaborados sobre temas del } \\
\text { curso y vigentes en el contexto } \\
\text { social, relacionados con la AF } \\
\text { o la corporalidad, utilizando re- } \\
\text { cursos tecnológicos. }\end{array}$ & $\begin{array}{l}\text { - Strava App/Geocaching } \\
\text { (capturas de pantalla sobre las } \\
\text { rutas o recorridos realizados } \\
\text { en las sesiones y exposición } \\
\text { de la experiencia). } \\
\text { - Exposición de trabajos en } \\
\text { grupo sobre cualquier blo- } \\
\text { que de contenido (uso de } \\
\text { Power Point, grabación audio- } \\
\text { visual o cualquier otro recurso } \\
\text { similar). }\end{array}$ \\
\hline \multirow{3}{*}{$4^{\circ} \mathrm{ESO}$} & \multirow{3}{*}{$\begin{array}{l}\text { Crit.EF.6.12. Utilizar efi- } \\
\text { cazmente las TIC en el } \\
\text { proceso de aprendizaje, } \\
\text { para buscar, seleccionar } \\
\text { y valorar informaciones } \\
\text { relacionadas con los con- } \\
\text { tenidos del curso, comu- } \\
\text { nicando los resultados y } \\
\text { conclusiones en el sopor- } \\
\text { te más adecuado. }\end{array}$} & $\begin{array}{l}\text { Est.EF.6.12.1. } \\
\text { Busca, procesa y analiza críti- } \\
\text { camente informaciones actua- } \\
\text { les sobre temáticas vinculadas } \\
\text { a la AF y la corporalidad utili- } \\
\text { zando recursos tecnológicos. }\end{array}$ & $\begin{array}{l}\text { - Trabajo monográfico sobre } \\
\text { un tema en concreto rela- } \\
\text { cionado con los bloques de } \\
\text { contenido. Descripción del } \\
\text { proceso de búsqueda (térmi- } \\
\text { nos utilizados, páginas o bus- } \\
\text { cadores), análisis (si ha con- } \\
\text { trastado o no la información } \\
\text { encontrada, indicando cómo } \\
\text { o con qué fuentes) y recursos } \\
\text { tecnológicos empleados para } \\
\text { su realización (móvil, tablet y } \\
\text { ordenador). }\end{array}$ \\
\hline & & $\begin{array}{l}\text { Est.EF.6.12.2. } \\
\text { Utiliza las TIC para profundizar } \\
\text { sobre contenidos del curso, } \\
\text { realizando valoraciones críti- } \\
\text { cas y argumentando sus con- } \\
\text { clusiones. }\end{array}$ & $\begin{array}{l}\text { - Proyecto de concienciación } \\
\text { sobre la salud, deporte o jue- } \\
\text { gos en el centro escolar (gra- } \\
\text { bación de entrevistas de audio } \\
\text { o vídeo, fotos sobre el patio, } \\
\text { recreo, zonas deportivas, bús- } \\
\text { queda de material e informa- } \\
\text { ción en internet) y conclusio- } \\
\text { nes sobre el tema y el trabajo. }\end{array}$ \\
\hline & & $\begin{array}{l}\text { Est.EF.6.12.3. } \\
\text { Comunica y comparte informa- } \\
\text { ción e ideas en los soportes y } \\
\text { en entornos apropiados. }\end{array}$ & $\begin{array}{l}\text { - Participación en el blog } \\
\text { (exposición y fundamentación } \\
\text { de la opinión basada en la in- } \\
\text { formación recopilada, su con- } \\
\text { traste posterior y la situación } \\
\text { actual de la temática). }\end{array}$ \\
\hline
\end{tabular}




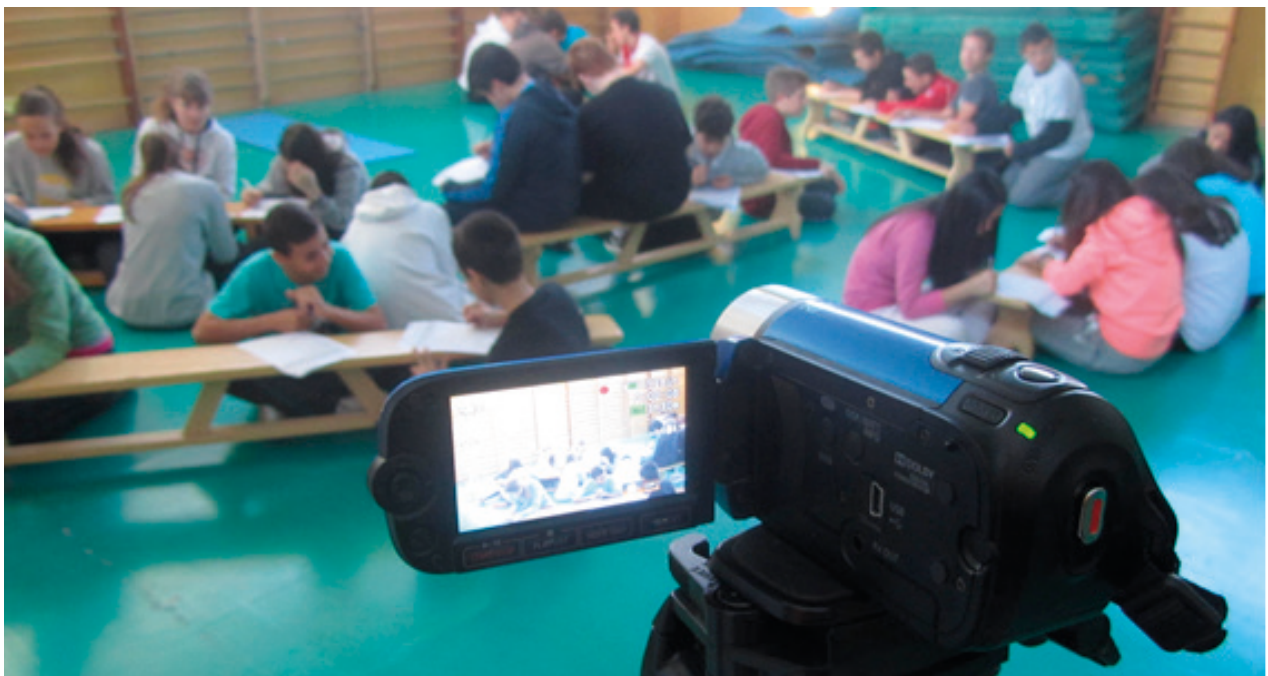

\section{TIC en "Sigue la Huella"}

\section{Blog}

El uso del blog y de una página web es algo totalmente accesible a cualquier centro o instituto. Sin embargo, exige que el profesorado actualice periódicamente la información para que el alumnado pueda consultarlo asiduamente.

De forma concreta, en el I.E.S. Sierra de Guara, centro donde se ha desarrollado el programa escolar "Sigue la Huella", se utiliza el blog con un doble fin. Por un lado, sirve para divulgar a la comunidad educativa los proyectos y acciones realizados en el centro y, por otro, almacena documentos sobre las diferentes materias (apuntes, actividades de ampliación o complementarias, cuestionarios, valoraciones, opiniones, comunicación de resultados, etc.).

Algunos ejemplos sobre los beneficios que aporta un blog a nivel educativo son los siguientes:

- Establece un sistema de interacción profesorado-alumnado y alumnado-grupo de iguales, vinculado al contexto educativo, fuera del aula.

- Facilita el auto-conocimiento, la reflexión y el espíritu crítico en los jóvenes a través del feedback que proporcionan los comentarios y reseñas de las publicaciones.

- Posibilita la utilización de multimedia, enriqueciendo y motivando el proceso de aprendizaje.

- Posibilita nuevas formas de comunicación entre personas de dentro y fuera de la comunidad educativa y da visibilidad a proyectos educativos.

- Propicia nuevos y diversos vínculos y redes sociales entre personas de todo el mundo que se unen por intereses comunes.

- Facilita el conocimiento de otras realidades y personas cercanas o lejanas.

- Se rompen las restricciones de tiempo y espacio que impone el aula.

Por otro lado, a través de la página web I.E.S. Sierra de Guara es posible conocer en mayor detalle los proyectos y acciones que se realizan en los diferentes niveles educativos que componen el centro (ESO, Bachillerato, Formación Profesional Básica, Grados medios y superiores). De este modo, el alumnado puede tener acceso a cualquier tipo de información, asignaturas, proyectos, etc. que se realizan en el centro educativo.

Respecto a la divulgación a la comunidad educativa de los proyectos y acciones realizados en el centro, cabe destacar que, normalmente, no se sube el contenido íntegro, sino que se suelen filtrar las fotografías (especialmente reduciendo el número de fotos de los alumnos/as), puesto que es una web de acceso público. Aun así, es un pilar fuerte que permite a las familias y a otros agentes de la comunidad educativa 
(profesores, institutos, futuras familias o alumnos/as que se vayan a matricular) poder hacer un seguimiento a distancia y en diferido, de los diferentes proyectos desarrollados en el centro educativo.

En relación al segundo fin, relativo al almacenamiento de documentos sobre las diferentes materias, existen una gran variedad de plataformas que permiten realizar esta función (Moodle, intranets, etc.) que, incluso, pueden ser más operativas que el propio blog. Sin embargo, la principal razón por la que se recomienda utilizar esta plataforma es, principalmente, para concentrar todo el contenido del centro en un mismo espacio virtual, evitando así, diversificar el contenido en varias plataformas. Por lo general, en el I.E.S. Sierra de Guara la web del centro incluye a la mayor parte de las asignaturas que se imparten en cada curso y nivel educativo (p.ej., asignaturas de ESO, Bachillerato, Formación Profesional, etc.).

Para finalizar, es importante destacar que, aunque se ha contrastado la eficacia de las TIC utilizadas en el programa escolar "Sigue la Huella", se sigue trabajando en la búsqueda y posible inclusión de otras herramientas tecnológicas relacionadas con esta temática.

\subsection{TIC EN EL PROFESORADO}

En este epígrafe se detalla cómo pueden utilizarse las TIC por parte del profesorado, no solo para favorecer el desarrollo de competencias en el alumnado, sino también para facilitar el proceso de enseñanza-aprendizaje del propio docente. Para ello se desglosan varios ejemplos prácticos utilizados en el programa escolar "Sigue la Huella".

\begin{tabular}{|c|c|c|}
\hline $\begin{array}{l}\text { Herramientas } \\
\text { para el } \\
\text { profesorado }\end{array}$ & $\begin{array}{c}\text { Competencias } \\
\text { clave }\end{array}$ & Ejemplos prácticos \\
\hline \multirow[t]{2}{*}{$\begin{array}{l}\text { Apoyo al } \\
\text { Alumnado }\end{array}$} & $\begin{array}{l}\text { Competencia } \\
\text { digital (CD) }\end{array}$ & $\begin{array}{l}\text { Página web: } \\
\text { Permite al alumnado acceder en cualquier momento a los con- } \\
\text { tenidos teóricos, prácticos o ampliaciones facilitadas por el do- } \\
\text { cente. } \\
\text { QR code: } \\
\text { Es una forma de sensibilizar al alumnado en el conocimiento y } \\
\text { uso de este tipo de códigos con la puesta en práctica de diferen- } \\
\text { tes unidades didácticas (ej., Orientación). }\end{array}$ \\
\hline & $\begin{array}{l}\text { Competencia } \\
\text { de aprender } \\
\text { a aprender (CAA) }\end{array}$ & $\begin{array}{l}\text { Proyección en pantallas: } \\
\text { Se visualizan las fotografías de las diferentes acciones llevadas } \\
\text { a cabo en el proyecto. }\end{array}$ \\
\hline $\begin{array}{l}\text { Gestión } \\
\text { en el aula }\end{array}$ & & $\begin{array}{l}\text { Quiz show app: } \\
\text { Mediante este tipo de aplicaciones, el docente puede elaborar } \\
\text { una serie de preguntas cortas o cuestionarios sobre los conte- } \\
\text { nidos realizados. A través de los teléfonos móviles, el alumna- } \\
\text { do puede ir respondiendo a las diferentes preguntas que se van } \\
\text { planteando. } \\
\text { Caladu-capas: } \\
\text { Este software puede utilizarse por el profesorado en la UD de } \\
\text { carrera de larga duración para gestionar la carga de trabajo que } \\
\text { debe realizar el alumnado en cada sesión. Este hecho permitirá } \\
\text { al alumnado conocer diferentes progresiones de trabajo para po- } \\
\text { der aplicarlas fuera del aula. }\end{array}$ \\
\hline
\end{tabular}




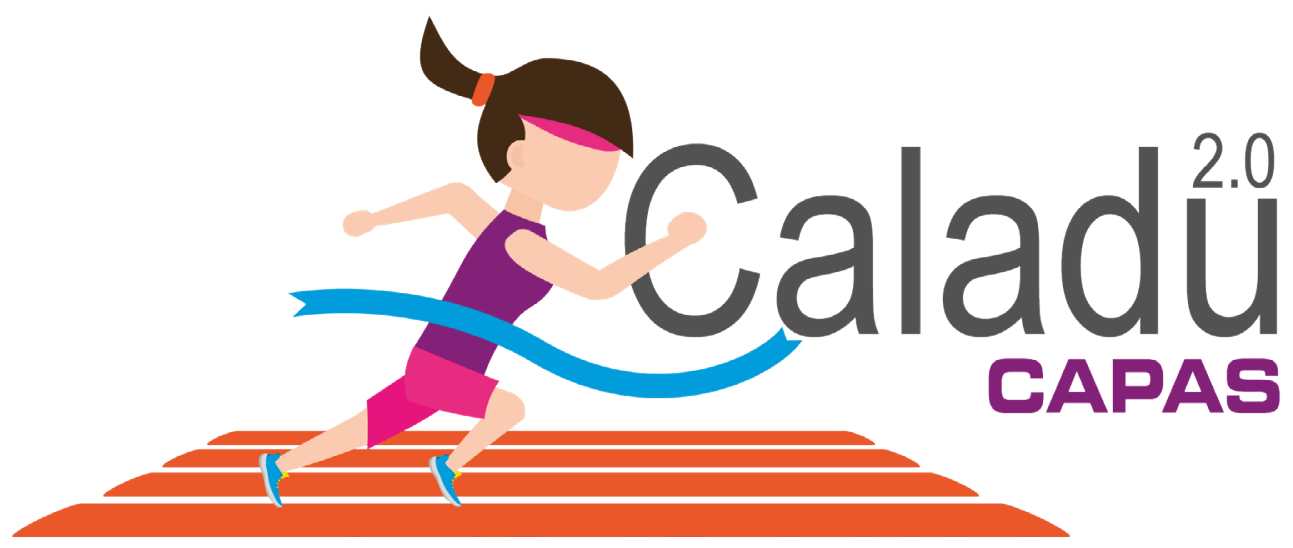

\section{Propuestas aplicadas con el profesorado en "Sigue la Huella":}

En cuanto a gestión del aula

\section{- CALADU-CAPAS}

CALADU es un software desarrollado por el grupo de investigación "Educación Física y Promoción de la Actividad Física" (EFYPAF) para ayudar a gestionar al profesorado la organización de los grupos y cargas de trabajo en unidades didácticas de carrera de larga duración. El programa, con la ayuda del Proyecto Capas-Ciudad, se ha actualizado pasándose a denominar CALADU-CAPAS. Actualmente este recurso se encuentra disponible en http://efypaf.unizar.es/recursos/cld.html

No podemos olvidar que la UD se configura a partir de determinados parámetros cuantitativos (número de metros a recorrer, tiempo de recuperación después de cada serie, \% de intensidad de carrera, etc.), pero también participan otros elementos de carácter cualitativo como, por ejemplo, la interacción entre el profesorado y alumnado y el trabajo en pequeños grupos de alumnos.

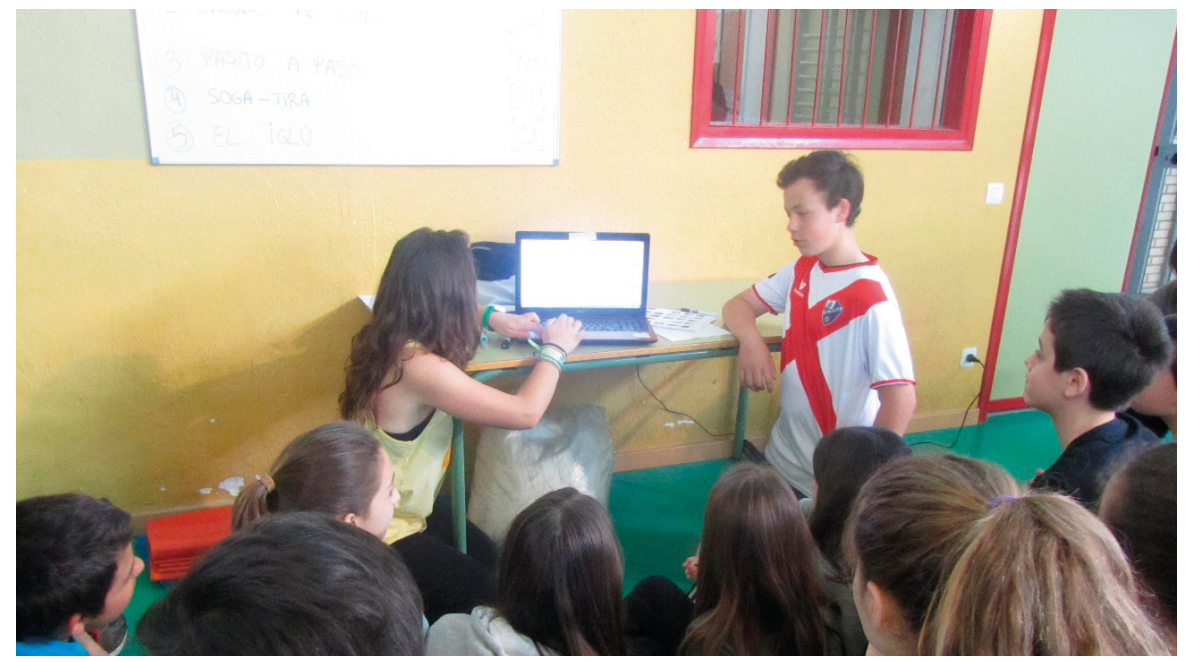




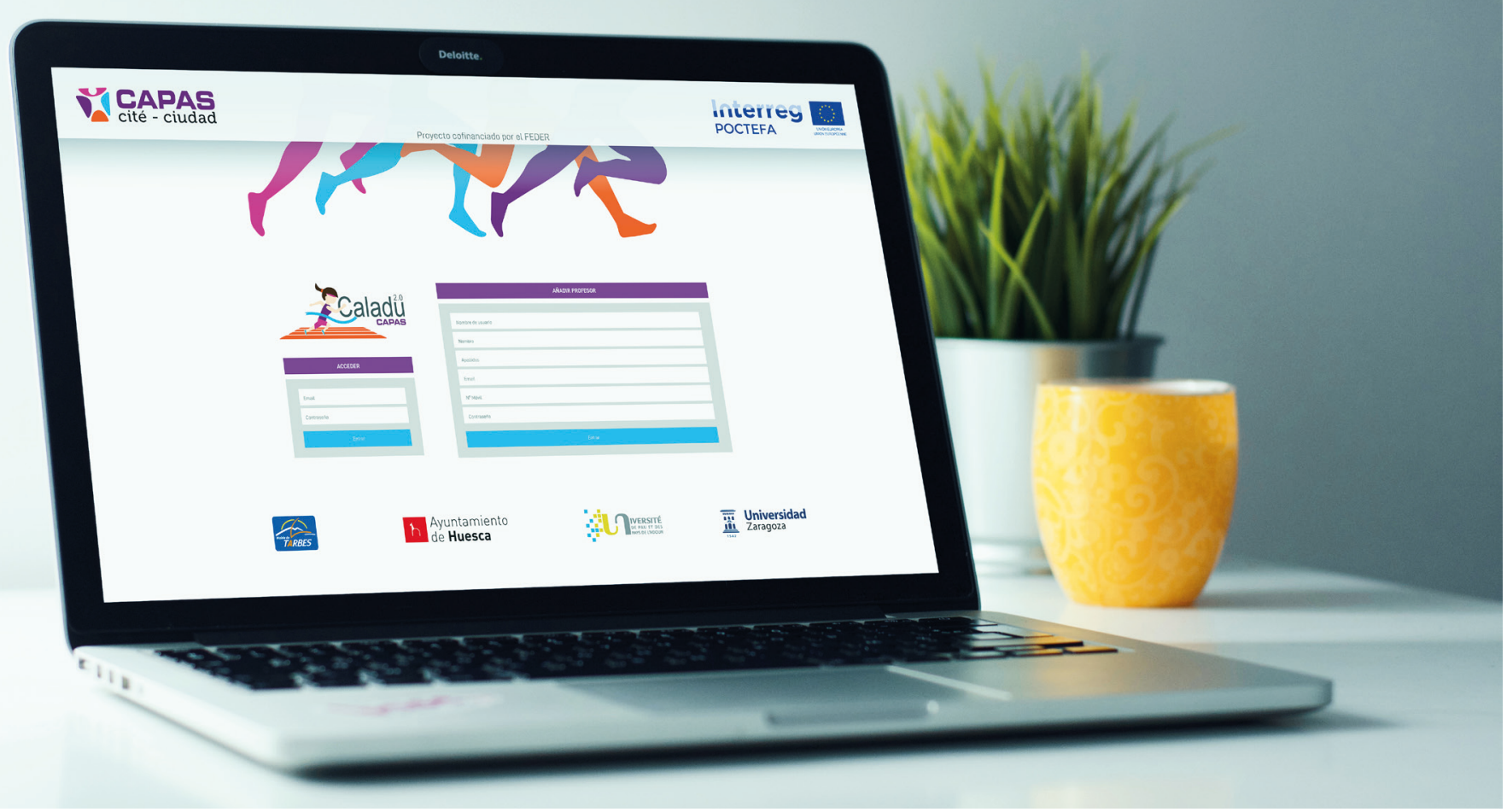

Esta UD convierte la enseñanza de la carrera de larga duración en una herramienta que ayuda a desarrollar en el alumnado tres aspectos:

- Hay un claro compromiso fisiológico adaptado a cada nivel.

- Hay un importante compromiso cognitivo que evoluciona con la edad (control de las vueltas que representan cada distancia o seguimiento de la frecuencia cardiaca mediante utilización de pulsómetros, etc.).

- Es muy importante el compromiso relacional: aceptación de las propias capacidades y de las de los demás, etc.

Las directrices dadas por el programa CALADU para la construcción de la UD de carrera de larga duración facilitan que se atiendan escrupulosamente los principios o fundamentos del acondicionamiento físico (la continuidad, la progresión, la gestión autónoma y la individualización). Además, señalamos que para cada una de las sesiones de la UD resultan fundamentales tres parámetros cuantitativos que son registrados con el programa CALADU: el volumen de trabajo, la intensidad del esfuerzo y la recuperación.

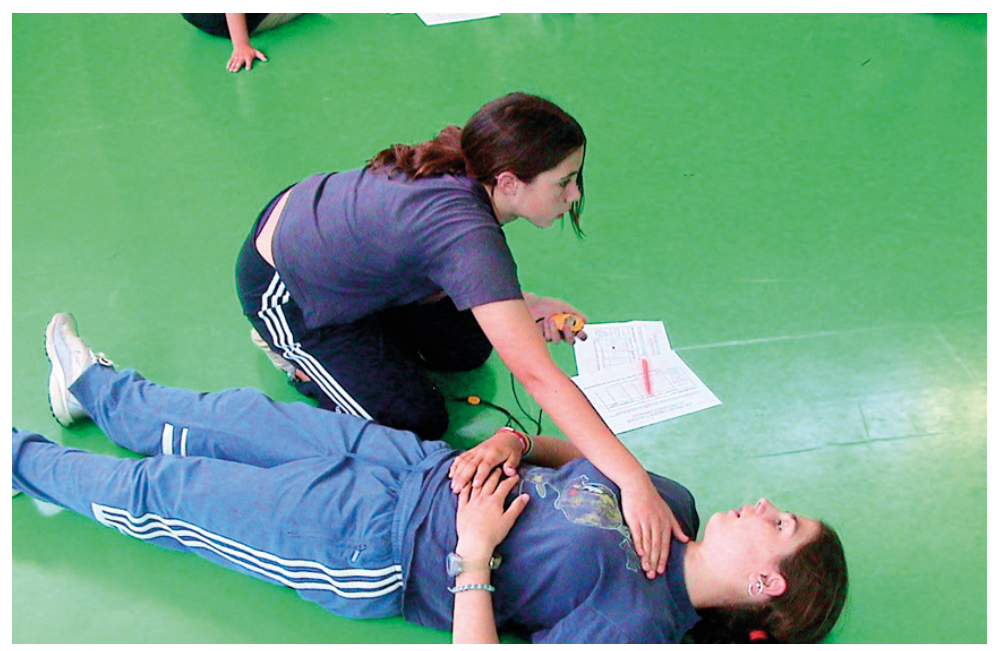


El software facilita la programación de las clases, atendiendo preferentemente a las siguientes opciones:

- Configurar variables globales de cada grupo-clase (número de sesiones de la unidad de aprendizaje, carga de trabajo en metros de carrera, en repeticiones y en recuperación del trabajo).

- Incluir configuraciones predefinidas listas para ser utilizadas.

- Permitir reutilizar configuraciones utilizadas en otros cursos, e, incluso, intercambiar dichas configuraciones con otros docentes.

- Gestionar la situación inicial de referencia permitiendo elegir varias situaciones de trabajo (ej., test de cinco minutos).

- División automática del alumnado por grupos de nivel, en función de la evaluación inicial, a partir de la velocidad aeróbica máxima.

- Asignación de una carga de trabajo individualizada para cada subgrupo.

- Generación automática o manual (en función de los criterios del docente) de grupos más reducidos (subgrupos) para un trabajo que requiera la máxima implicación por parte del alumnado.
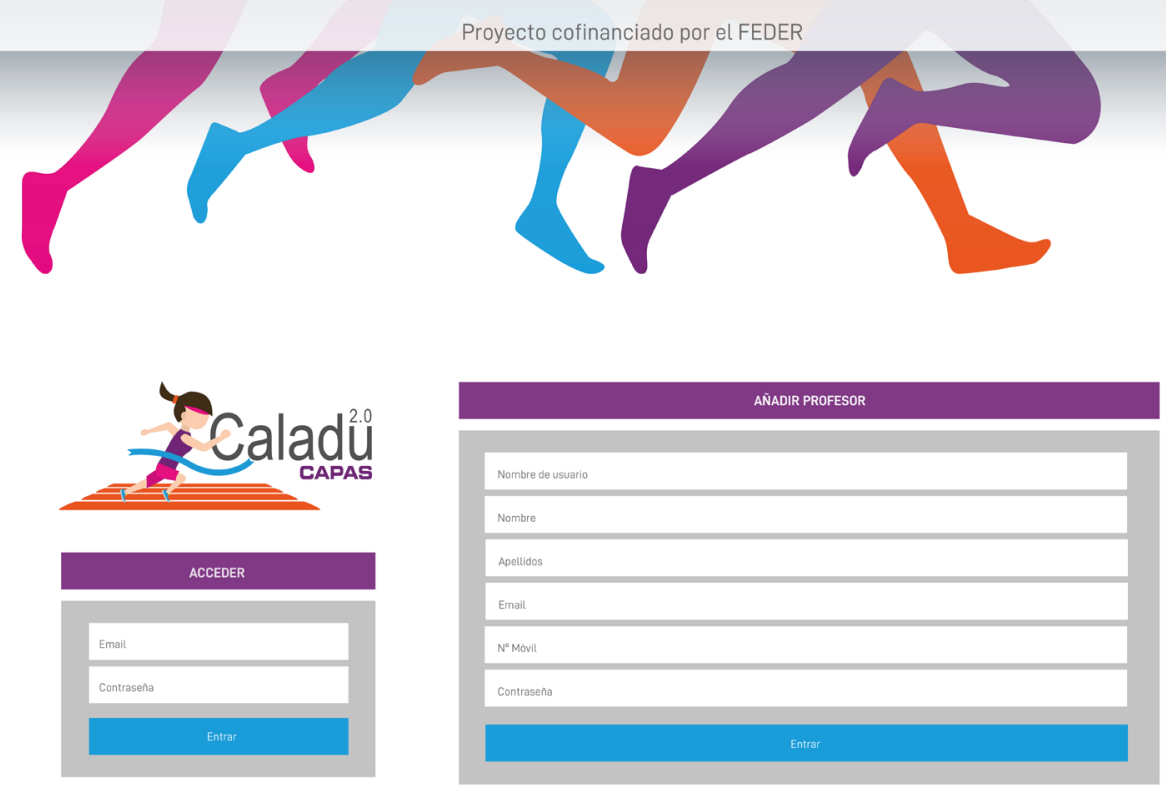
Además, en el diseño del programa, se han tenido en cuenta una serie de requerimientos que, sin afectar a la funcionalidad del programa, afectan a la filosofía que se le ha querido dotar. Entre los requerimientos no funcionales destacamos los siguientes:

- Uso sencillo y rápido del programa, utilizando las configuraciones predeterminadas. El programa permite guiar rápidamente al docente para configurar la UD con muy poca inversión de tiempo. Por otro lado, se quiere obtener la máxima flexibilidad dando la opción de personalizar gran parte de los parámetros.

- Máxima flexibilidad para adaptarse a los diferentes contextos en los que puede desarrollar la función docente el profesorado de EF (diferente nivel de alumnado, cursos, espacios, sesiones que puede destinar a la unidad, etc.).

- Permitir una gestión rápida y eficaz del alumnado a lo largo de toda la escolaridad (Educación Primaria y Secundaria) en la que se puede repetir la unidad de aprendizaje continuamente, curso tras curso.

También destacamos que su uso constituye, sin duda, una buena oportunidad para el trabajo interdisciplinar, en ocasiones infrautilizado (Generelo y otros, 2009).

A modo de conclusión, es preciso destacar la importancia que ha tenido la creación e implementación de este software en el programa escolar "Sigue la Huella". Este no solo ha beneficiado y facilitado la tarea del profesorado a la hora de organizar y gestionar la UD, sino que, además, el propio alumnado ha tomado conciencia de su aprendizaje. Se permite, de esta forma, poder llevar un control y gestión correcta de la progresión del alumnado, así como recibir un feedback y refuerzo individualizado o en pequeños grupos, por parte del docente.

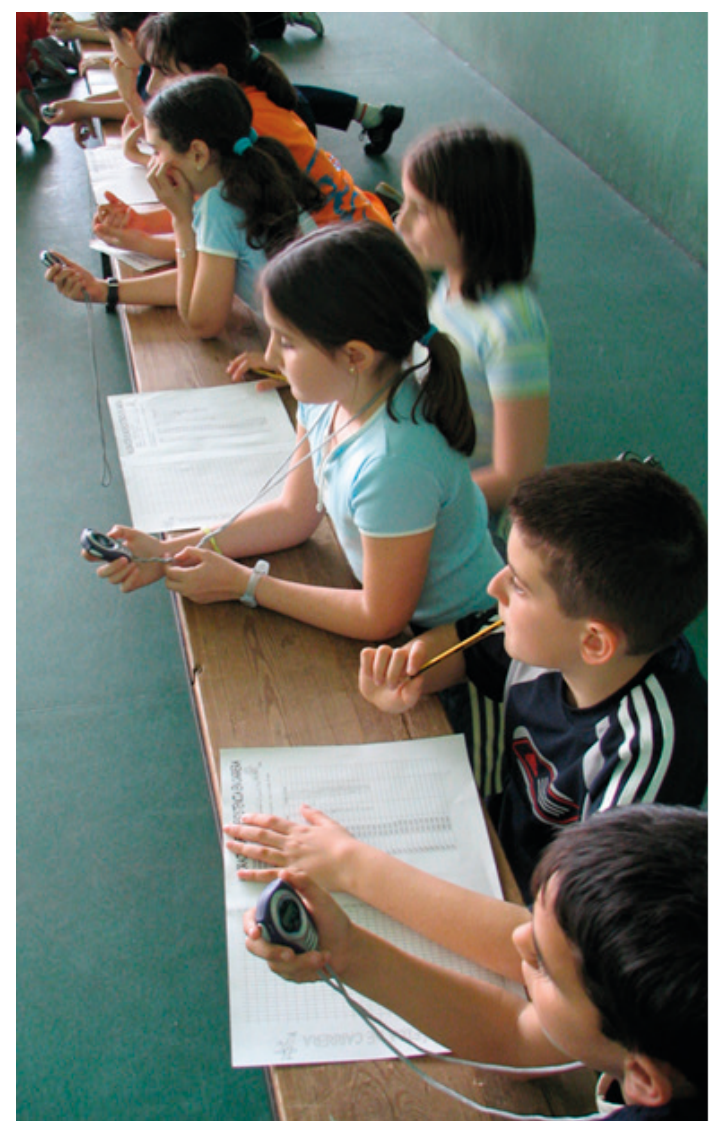


En cuanto al desarrollo de competencias del alumnado destaca:

- Proyección en pantallas

El uso de la proyección de vídeos y fotografías en monitores y pantallas de los centros educativos puede ser un recurso muy eficaz a la hora de fomentar la participación del alumnado en los programas y acciones llevadas a cabo. Este tipo de recursos, normalmente, se encuentran infrautilizados o infravalorados por el profesorado de los institutos. Como vamos a ver a continuación, la puesta en práctica de esta propuesta no solo es viable, sino que es altamente recomendada en aquellos centros que las tengan.

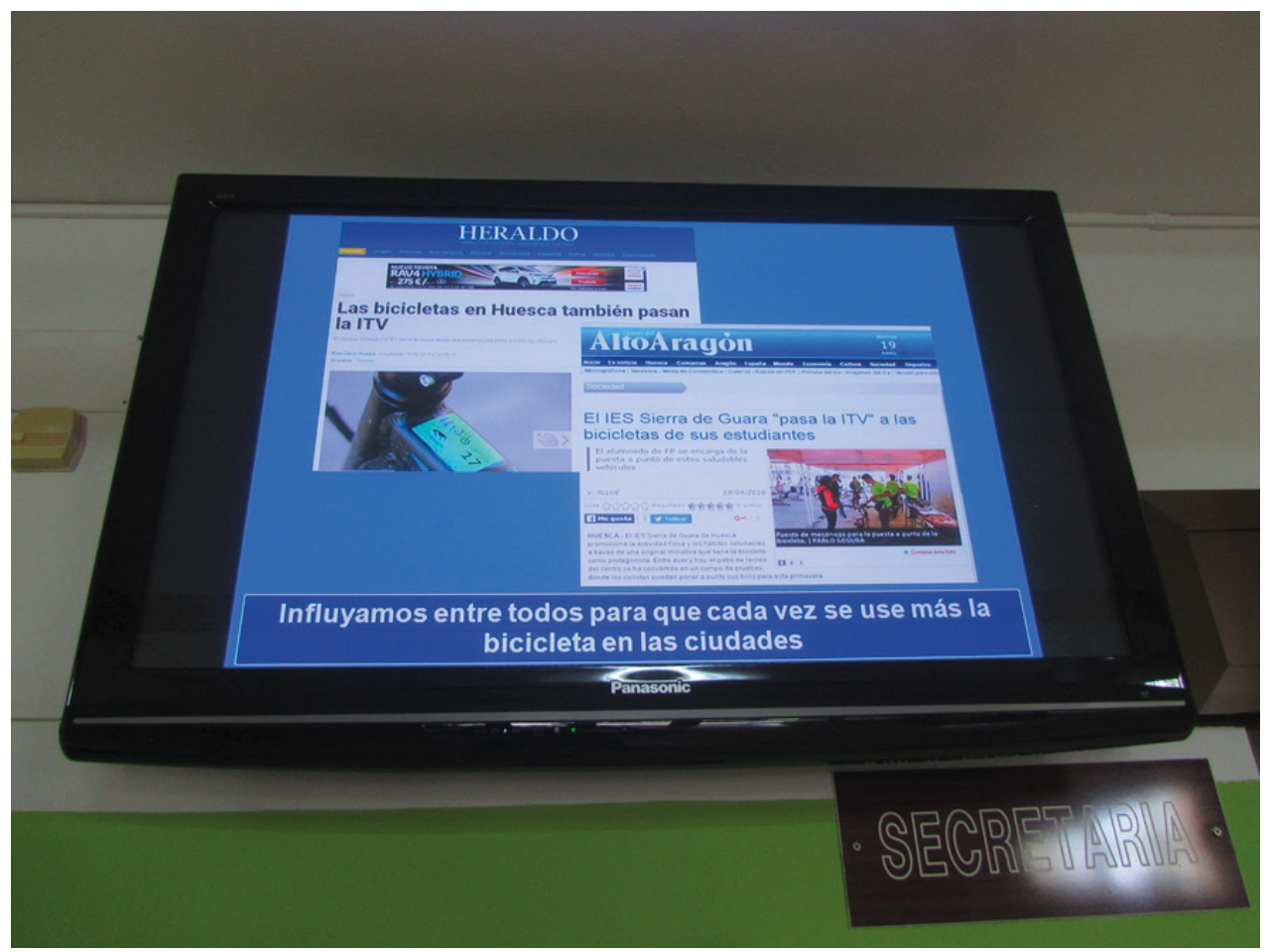

Dentro del programa escolar "Sigue la Huella", el visionado de material audiovisual en zonas comunes se ha llevado a cabo en el I.E.S. Sierra de Guara. A modo de contextualización, destacamos que este centro se caracteriza por tener varios monitores o pantallas en las zonas comunes del centro, especialmente en el hall principal, donde se encuentran las áreas de conserjería, secretaría y dirección. Esta zona supone un espacio de paso y de encuentro por el que transita la mayor parte del alumnado y profesorado a lo largo del día.

Este tipo de proyecciones se realizan en el centro con el objetivo de divulgar a toda la comunidad educativa las diferentes acciones que se llevan a cabo (intercambios, recepción de alumnado externo, programa mentor, recreos divertidos, proyectos internos del centro, etc.), actos o eventos deportivos y recreativos del contexto socio-cultural (inspección técnica de bicicletas (ITB), jornada cultural aragonesa, encuentros inter-centros, excursiones, etc) y reconocimientos al centro, especialmente del alumnado (premios recibidos, notas de prensa, distinciones, participación en congresos, etc).

Es una forma de dar visibilidad y mantener informada a la comunidad educativa acerca de las iniciativas que se ponen en práctica en el centro educativo. El objetivo de estas proyecciones se focaliza en:

1. Involucrar y empoderar mediante su visualización a toda la comunidad educativa, favoreciendo así su participación en las diferentes acciones.

2. Buscar que el alumnado se sienta partícipe y sea consciente del para qué y del porqué de llevar a cabo estas acciones o proyectos en el centro. De otra forma, su participación se reduciría a seguir una inercia concreta, perdiendo así su perspectiva holística. 
La imagen, con estos recursos, adquiere gran influencia y a través de ella queremos conseguir los objetivos educativos de:

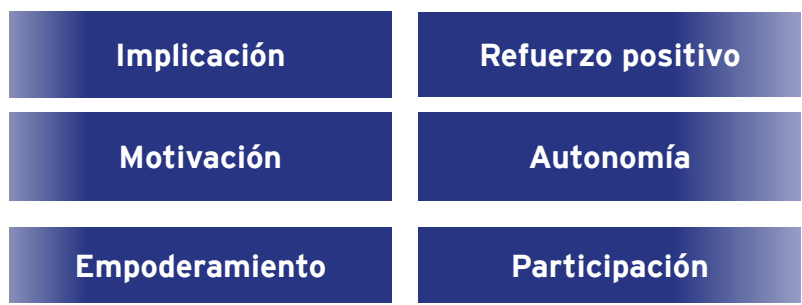

Relaciones sociales

Por ello, deberemos tener en cuenta a la hora de seleccionar las imágenes que estas:

- Compartan información, conceptos y representaciones.

Generen procesos reflexivos.

Transmitan ideas, valores y sentimientos.

- Generen sensaciones, atracción e interés.

A nivel educativo y dentro del programa escolar "Sigue la Huella" (donde buscamos la promoción de hábitos saludables), hemos tenido en cuenta los siguientes aspectos a la hora de seleccionar las imágenes:

- Diversidad de género.

- Diversidad étnica y cultural.

- Coherencia con el mensaje que queremos transmitir.

- Emociones positivas como felicidad y alegría.

- Valores como el esfuerzo, el interés y la cooperación.

El objetivo es mostrar que en todas las actividades puede participar todo el alumnado. Se busca además mitigar los tabúes y clichés que se arrastran a nivel social desde hace décadas (ej., actividades para chicos, actividades para chicas, actividades en las que el alumnado con sobrepeso o con diversidad funcional no se ve representado o capacitado, etc.).

Por otro lado, es fundamental que el mensaje educativo que queremos transmitir sea coherente con las imágenes, por lo que si queremos incentivar la participación del alumnado deberán verse proyectadas imágenes en situaciones favorables de cooperación, diversión, interacción, asombro, felicidad, así como aquellas que fomenten la adopción de hábitos saludables.

Para concluir este epígrafe, es conveniente destacar que, para poder llevar a cabo estas estrategias de montaje, producción/creación de contenido y, finalmente, promoción, es necesario involucrar a todo el profesorado. La existencia de un equipo directivo y profesorado comprometido para llevar a cabo estas actividades, siguiendo la correspondiente hoja de ruta o planificación, facilitará que algunas de estas acciones se puedan llevar a cabo.

El profesorado de EF, por la idiosincrasia de la asignatura, se configura especialmente determinante en la participación en este tipo de estrategias debido a que el alumnado trabaja contenidos relativos a hábitos saludables.

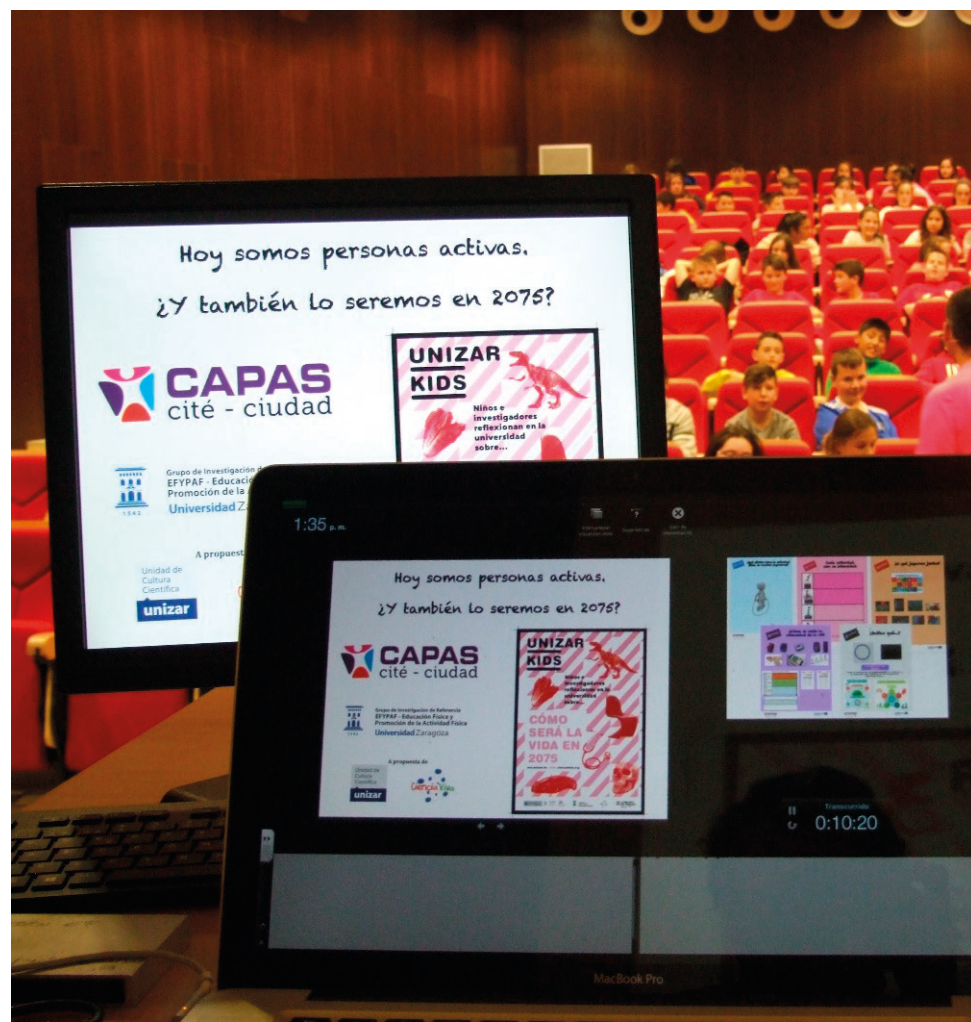




\section{BARRERAS}

Aquí se detallan las principales barreras y limitaciones derivadas del uso o introducción en el aula de las TIC, destacando aquellas derivadas de los ejemplos implementados en el programa escolar "Sigue la Huella".

\section{1. ¿QUÉ SE ENTIENDE POR BARRERAS EN EL USO DE LAS TIC?}

Por barreras nos referimos a las dificultades o limitaciones con que nos encontramos como docentes a la hora de implementar las TIC en el contexto escolar. Estas barreras pueden ser de diferente tipología e índole. Existen barreras estructurales (problemas para incorporar las TIC al aula), materiales (problemas para adquirir las TIC en el centro, debido a su elevado coste), personales (problemas de aceptación en el aula por parte del alumnado y/o del profesorado) y formativas (problemas de manejo y desempeño correcto con las $\mathrm{TIC}$ ).

Centrándonos de nuevo en las principales barreras percibidas en los ejemplos puestos en el programa escolar "Sigue la Huella", se destaca:

1. Caladu: Las barreras percibidas por los docentes son el registro manual de los datos de todo el alumnado (entre sesión y sesión) y la necesidad de recibir un tipo de formación previa. Asimismo, requiere que el centro o el propio profesorado disponga de este software. Aunque es gratuito, gran parte del profesorado no conoce esta herramienta.

Puede descargarlo aquí: http://efypaf.unizar.es/recursos/caladu.html

Las barreras percibidas por el alumnado son la dificultad en la comprensión del funcionamiento del software (cómo se generan las estimaciones de tiempo) y registrar correctamente los parámetros de los compañeros (cuando se toman los datos del tiempo de carrera del compañero o en pequeños grupos).

2. Proyección en las pantallas del centro: el principal problema es que solo pueden visualizarse en el recreo, al inicio y al final de las clases y en los descansos entre clase y clase. Esta estrategia exige el montaje de las fotografías y también requiere que haya una persona pendiente de reproducir manualmente el visionado de fotografías.

3. Blog/web: como barreras más importantes se identifica la dificultad de acceso a internet por una parte de la comunidad educativa y la dificultad de manejo de la web por parte de algunos usuarios. Esto se produce principalmente en personas adultas en las que no ha existido una infancia tan ligada a las TIC.

Aunque los docentes muestran su predisposición para formarse y adquirir competencias para trabajar con la TIC, todavía nos queda un largo camino por recorrer.

Uno de los principales problemas que puede provocar el uso de las TIC es un uso inadecuado, esto puede provocar que la educación pierda algunas de sus características esenciales o se desnaturalice.

Por otro lado, el hecho de que exista un avance tecnológico y este se incluya en el sistema educativo, no es obligatoriamente un síntoma de una mejora en el proceso de enseñanza-aprendizaje del alumnado. Autores como Correa y De Pablos (2009) creen que la introducción de las tecnologías en los centros educativos no obedece a intereses educativos, sino económicos, por lo que podría producirse una separación del verdadero sentido de la utilización didáctica de estos recursos en los centros educativos si no se utilizan correctamente. De hecho, algunas voces críticas como Rodríguez (2010) manifiestan que la integración de las TIC en modelos formativos no adecuados no solo no mejoran el aprendizaje sino que lo empeoran, incrementando la carga de trabajo, tanto al profesorado como a los estudiantes. 


\section{2.}

CONCLUSIONES DEL PROGRAMA "SIGUE LA HUELLA"

En relación con el marco teórico detallado en la introducción y, tras la aplicación de la intervención mencionada previamente, se destaca lo siguiente:

- Tanto la implementación como el uso de las TIC en el aula y en el centro educativo han servido como apoyo, y no como fin, a la hora de implementar los proyectos o intervenciones mencionados. En este sentido, las TIC se han caracterizado por ser una herramienta muy poderosa, tanto para ayudar al docente a realizar la progresión del aprendizaje del alumnado (ej., mediante el software CALADU), como para potenciar las estrategias de promoción y difusión (ej., pantallas, blog, etc.).

- Por consiguiente, parece razonable y oportuno destacar que las TIC han tenido un papel representativo dentro del programa escolar "Sigue la Huella", así como en otras áreas de conocimiento en las que se han implementado dentro del I.E.S. Sierra de Guara.

Para ello, es necesario que el profesorado haga un uso responsable de las TIC en el aula. Esta guía debe servir como orientación y consulta para cualquier docente que quiera implementar alguna de estas propuestas en el aula, así como para todos aquellos profesionales que tengan una especial curiosidad o preocupación en cuanto a cómo apoyarse en el uso de las TIC para mejorar su práctica profesional.

Asimismo, este documento se ha planteado como una guía orientativa para el profesorado, especialmente para el de EF, que desee ayudarse de las TIC para promover hábitos saludables en el alumnado. No obstante, cabe destacar que las propuestas planteadas en la presente guía se han realizado en un contexto específico, por lo que cada centro educativo deberá adaptar dichas estrategias en función de sus características y necesidades.

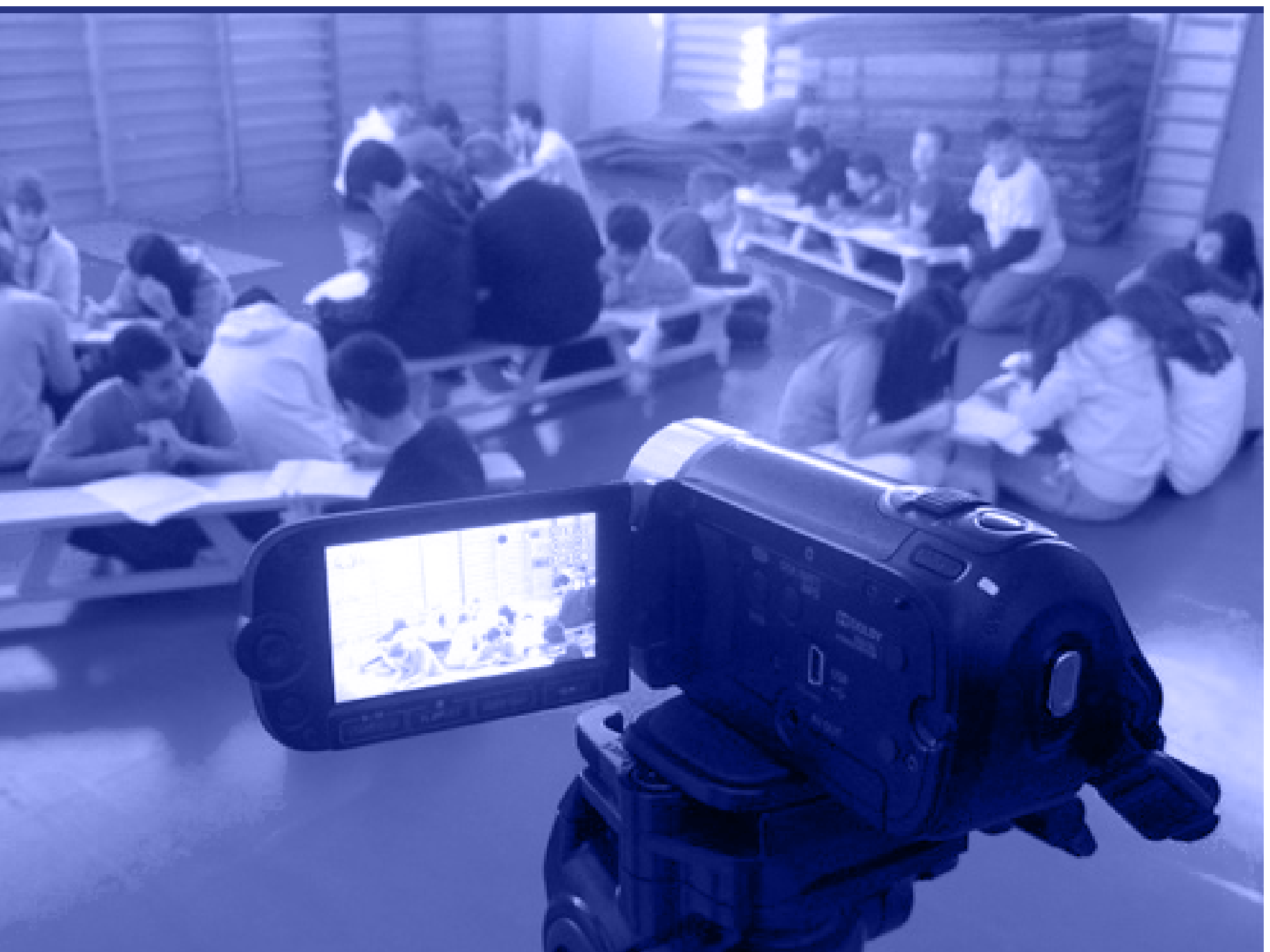




\section{Biblografía}

Adelantado-Renau, M., Diez-Fernandez, A., Beltran-Valls, M. R., Soriano-Maldonado, A., \& Moliner-Urdiales, D. (2018). The effect of sleep quality on academic performance is mediated by Internet use time: DADOS study. Jornal de Pediatria, S0021-7557(18)30013-5.

Belton, S., Wesley, O., Meegan, S., Woods, C., \& Issartel, J. (2014). Youth-physical activity towards health: Evidence and background to the development of the Y- PATH physical activity intervention for adolescents. BMC Public Health, 14(1), 122- 134.

Carrion, C., Arroyo Moliner, L., Castell, C., Puigdomènech, E., Gómez, S. F., Domingo, L., \& Espallargues, M. (2016). Utilización del teléfono móvil para el fomento de hábitos saludables en adolescentes. Estudio con grupos focales. Revista Española de Salud Pública, 90(3), 1-11.

Carta Internacional de la Educación física, la actividad física y el deporte (2015). UNESCO.

Chaput, J. P., Carson, V., Gray, C. E., \& Tremblay, M. S. (2014). Importance of all movement behaviors in a 24 hour period for overall health. International Journal of Environmental Research and Public Health, 11(12), 12575-12581.

Common Sense Media (2017). The Common Sense census: media use by kids age zero to eight. Recuperado de: goo.gl/pb2w72.

Conde, E. (2018). El uso de la tecnología de la información y la comunicación entre adolescentes. International Journal of Developmental and Educational Psychology, 2(1), 13-22.

Corrales, A. R. (2009). La integración de las Tecnologías de la información y comunicación (TIC) en el Área de Educación Física. Hekademos: Revista Educativa Digital, 4, 45-56.

Correa, J. M., \& de Pablos, J. (2009). Nuevas tecnologías e innovación educativa. Revista de Psicodidáctica, 14(1), 133-145.

Escaravajal-Rodríguez, J. C. (2018). Los códigos QR en educación física: carrera de orientación. Pensar en movimiento: Revista de Ciencias del Ejercicio y la Salud, 16(1), 1-14.

García, A., Callejo, J., \& Walzer, A (2004). Los niños y los jóvenes frente a las pantallas. Madrid, Ministerio de Trabajo y Asuntos sociales.

Generelo, E., Julián, J. A., \& Zaragoza, J. (2009). Tres vueltas al patio. La carrera de larga duración en la escuela. Zaragoza: Inde.

Gutiérrez, M. (2014). Relaciones entre el clima motivacional, las experiencias en educación física y la motivación intrínseca de los alumnos. Retos. Nuevas tendencias en Educación Física, Deporte y Recreación, 26, 9-14.

Gómez, D. M., Veiga, O. L., Zapatera, B., Cabanas-Sánchez, V., Gomez-Martinez, S., Martinez-Hernández, D., \& Marcos, A. (2012). Patterns of sedentary behavior and compliance with public health recommendations in Spanish adolescents: the AFINOS study. Cadernos de Saúde Pública, 28(12), 2237-2244.

Holzinger, K., Lehner, M., Fassold, M., \& Holzinger, A. (2011). Archaeological scavenger hunt on mobile devices: From e-education to e-Business: A triple adaptive mobile Application for supporting experts, tourists and children. In e-Business (ICE-B), 2011 Proceedings of the International Conference on (pp. 1-6). IEEE.

Krishnaswami, J., Martinson, M., Wakimoto, P., \& Anglemeyer, A. (2012). Community-engaged interventions on diet, activity, and weight outcomes in US schools: a systematic review. American Journal of Preventive Medicine, 43(1), 81-91. 
Lai, H. C., Chang, C.Y., Li, W. S., Fan, Y. L., \& Wu, Y. T. (2013). The implementation of mobile learning in outdoor education: application of QR codes. British Journal of Education Technology, 44(2), 57-62.

Larraz, A. (2004). Los dominios de acción motriz como base de los diseños curriculares en Educación Física: el caso de la comunidad autónoma de Aragón en Educación Primaria.

Lemos, A. (2002). Cibercultura: la tecnología y la vida social en la cultura contemporánea. Porto Alegre: Sulina.

Lévy, P. (1999). Cibercultura. Rio de Janeiro: Editora 34.

Ley Orgánica 1/1990, de 3 de octubre, de Ordenación General del Sistema Educativo (LOGSE).

Ley Orgánica 10/2002, de 23 de diciembre, de Calidad de la Educación (LOCE).

Ley Orgánica 2/2006, de 3 de mayo, de Educación (LOE).

Ley Orgánica 8/2013, de 9 de diciembre, para la Mejora de la Calidad Educativa (LOMCE).

Lonsdale, C., Rosenkranz, R. R., Peralta, L. R., Bennie, A., Fahey, P., \& Lubans, D. R. (2013). A systematic review and meta-analysis of interventions designed to increase moderate-to-vigorous physical activity in school physical education lessons. Preventive Medicine, 56(2), 152-161.

López-Pastor, V.M. \& Gea-Fernández, J.M. (2010). Innovación, discurso y racionalidad en educación física. Revisión y prospectiva. Revista Internacional de Medicina y Ciencias de la Actividad Física y el Deporte, 10(38), 245-270.

Mielgo-Ayuso, J., Aparicio-Ugarriza, R., Castillo, A., Ruiz, E., Avila, J. M., Aranceta-Bartrina, J., ... González-Gross, M. (2017). Sedentary behavior among Spanish children and adolescents: findings from the ANIBES study. BMC Public Health, 17, 94.

Ministerio de Sanidad, Servicios Sociales e Igualdad (2018). Actividad Física para la Salud y Reducción del Sedentarismo. Recomendaciones para la población. Estrategia de Promoción de la Salud y Prevención en el SNS. Madrid.

Orden de 6 de mayo de 2005, del Departamento de Educación, Cultura y Deporte, por la que se aprueba el currículo de la Educación Primaria para la Comunidad Autónoma de Aragón. (BOA, 5 de julio de 2005).

Organización Mundial de la Salud. (2010). Global recommendations on physical activity for health. Extraído el 12 de junio de 2016 desde: http://whqlibdoc.who.int/publications/2010/9789241599979 eng.pdf

Parlebas, P. (1981). Contribución al léxico en las ciencias de la acción motriz. París: INSEP.

Perlman, D. J. (2015). Help motivate the amotivated by being a supportive teacher. Physical Education and Sport Pedagogy, 20(2), 204-214.

Prat, Q., Camerino, O., \& Coiduras, J. L. (2013). Introducción de las TIC en educación física. Estudio descriptivo sobre la situación actual. Apunts. Educació Física i Esports, 113, 37-44.

Rodríguez, R. S. (2010). El impacto de las TIC en la transformación de la enseñanza universitaria: repensar los modelos de enseñanza y aprendizaje Teoría de la Educación: Educación y Cultura en la Sociedad de la Información, 11(1), 32-68.

Román, P. (2012). Diseño, elaboración y puesta en práctica de un observatorio virtual de códigos QR. @ tic, Revista d'innovació Educativa, 9, 96-107.

Ryan, R. M., \& Deci, E. L. (2000). Intrinsic and extrinsic motivations: Classic definitions and new directions. Contemporary Educational Psychology, 25(1), 54-67.

Sallis, J. F., Cervero, R. B., Ascher, W., Henderson, K.A., Kraft, M.K., \& Kerr, J. (2006). An ecological approach to creating active living communities. Annual Review of Public Health, 27, 297-322. 
Sallis, J. F., Owen, N., \& Fisher, E. B. (2008). Ecological models of health behavior. In K. GIanz,B.K.Rimer, \& K. Viswanath (Eds.), Health behavior and health education: theory, research, and practice (pp. 465485). San Francisco, CA: Jossey-Bass.

Sevil, J., Abós, A., Generelo, E., Aibar, A., \& García-González, L. (2016). Importancia del apoyo a las necesidades psicológicas básicas en la predisposición hacia diferentes contenidos en Educación Física. Revista Retos. Nuevas tendencias en Educación Física, Deporte y Recreación, 29, 3-8.

Sevil, J., García-González, L., Abós, A., Generelo, E., \& Aibar, A. (2019). Can high schools be an effective setting to promote healthy lifestyles? Effects of a multiple behaviour change intervention in adolescents. Journal of Adolescent Health, 64, 478-486.

Telama, R., Yang, X., Viikari, J., Valimaki, I., Wanne, O., \& Raitakari, O. (2005). Physical activity from childhood to adulthood: A 21-year tracking study. American Journal of Preventive Medicine, 28(3), 267-273.

Tremblay, M. S., Carson, V., Chaput, J. P., Connor, S., Dinh, T., Duggan, M., ... Zehr, L. (2016). Canadian 24-hour movement guidelines for children and youth: an integration of physical activity, sedentary behaviour, and sleep. Applied Physiology, Nutrition, and Metabolism, 41(6), 311-327.

United Nations Educational, Scientific and Cultural Organization (2016). Directrices para las políticas de aprendizaje móvil. París, Francia: Autor.

Valencia-Peris, A., Devís-Devís, J., \& Peiró-Velert, C. (2014). El uso sedentario de medios tecnológicos de pantalla: perfil sociodemográfico de los adolescentes españoles. Retos. Nuevas tendencias en Educación Física, Deporte y Recreación, 26, 21-26.

Welk, G. J. (1999). The Youth Physical Activity Promotion Model: A conceptual bridge between theory and practice. Quest, 51(1), 5-23. 

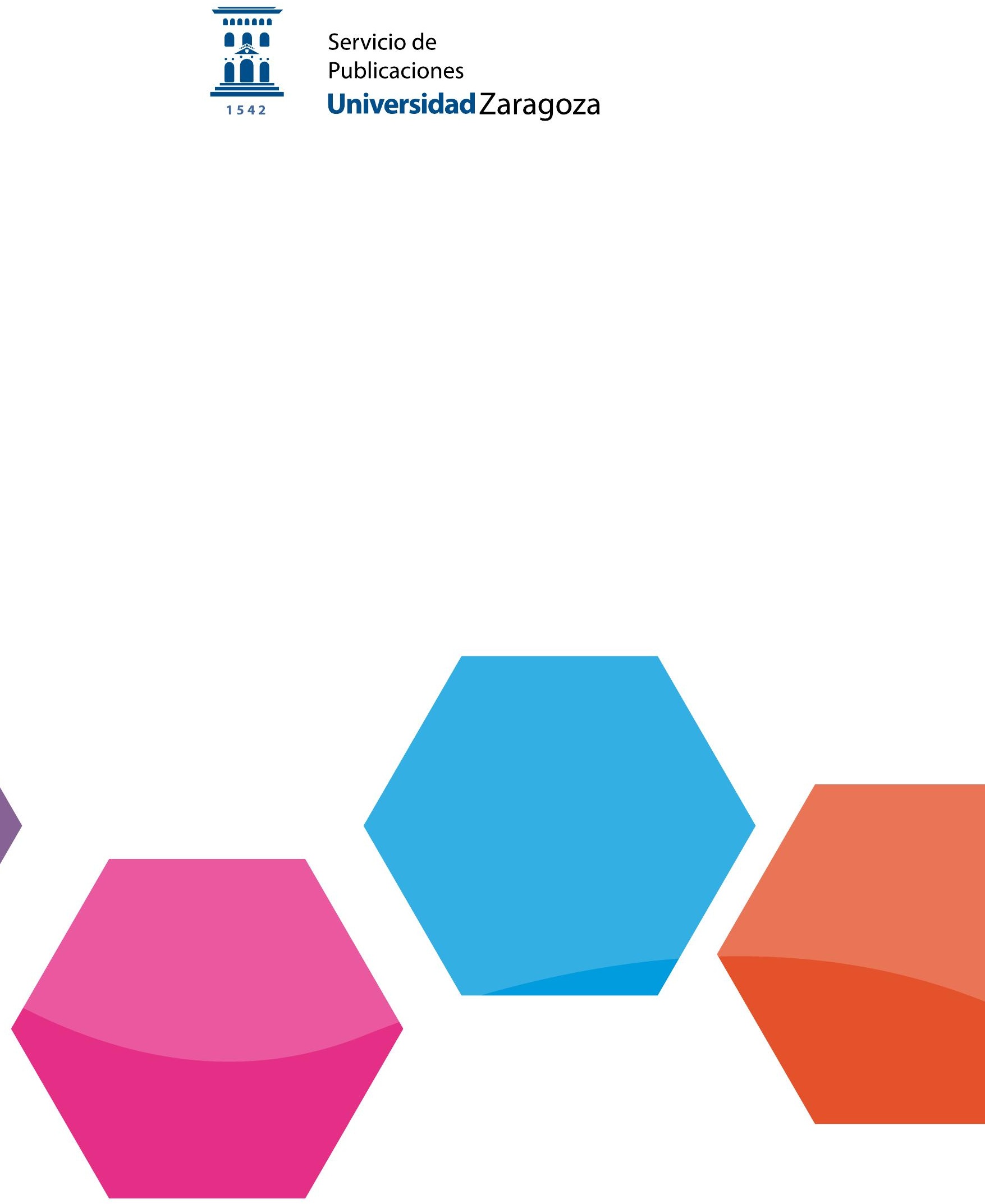

Interreg

POCTEFA 